\title{
Simulation of the Progression of the COVID-19 Disease in Northwest Syria Using Basic and Adjusted SIR Model
}

Orwa Al Abdulla ( $\sim$ orwaabdulla@hotmail.com )

University of Eastern Finland - Kuopio Campus: Ita-Suomen yliopisto - Kuopion kampus https://orcid.org/0000-0002-2294-0429

Agneta Kallström

University of Eastern Finland - Kuopio Campus: Ita-Suomen yliopisto - Kuopion kampus

Jussi Kauhanen

University of Eastern Finland - Kuopio Campus: Ita-Suomen yliopisto - Kuopion kampus

Camilo Valderrama

University of Eastern Finland - Kuopio Campus: Ita-Suomen yliopisto - Kuopion kampus

\section{Research Article}

Keywords: COVID-19, coronavirus, SIR model, pandemic, Northwest Syria, emergency, humanitarian, conflict

Posted Date: March 18th, 2021

DOI: https://doi.org/10.21203/rs.3.rs-339649/v1

License: (c) (1) This work is licensed under a Creative Commons Attribution 4.0 International License. Read Full License 
Institute of Public Health and Clinical Nutrition University of Eastern Finland UEF

Kuopio, Finland

March, $17^{\text {th }}, 2021$

Editors' office

Journal: Conflict and Health

Dear Editor-in-Chief,

Please find enclosed our manuscript entitled "Simulation of the Progression of COVID-19 Outbreak in Northwest Syria Using Basic and Adjusted SIR Model" For consideration by your journal. This research could be the first-ever COVID-19 progression simulation in a conflict-affected area using the SIR model. Furthermore, this study is among the few studies, if not the only one, that adjusts the SIR model with a confounding factor to deduce more realistic and intuitive results, on which the hospital utilization was projected in Northwest Syria (NWS). The research results indicate the required resources based on the simulation according to the basic and adjusted SIR model and compare them with the existing resources.

The situation in Syria is very particular. While the number of cases globally increases, the incidence rate of COVID-19 in NWS is dramatically decreasing according to the surveillance system. There is no rigorous evidence that the majority of people in NWS had contracted the diseases, and the number of cases, therefore, is expected to increase, especially with the collapsed health system and lack of basic health determinants. Nonetheless, the current figures in NWS are far away from the expectations. This study is a valuable initiative to systematically look at the progression of the outbreak in NWS to understand the relevant context of the outbreak in a conflict context. Furthermore, the research is a fundamental building block from which multiple research questions and assumptions would erupt. In this study, the evolution of COVID-19 disease in Northwest Syria (NWS); a protracted conflict area, and how the SIR model (Susceptible S, Infectious, and Removed R cases) could simulate the progress of the outbreak was discussed over the period from July 9, 2020, when the first COVID-19 case was confirmed, until July 8, 2021. The study's primary objective is to provide evidence-based answers for burning questions raised by humanitarian actors and decision-makers since the start of the outbreak in NWS. The research results and recommendations are considered to be crucial for donors and stakeholders to efficiently utilize and channel resources for COVID-19 response in a region witnessing a noticeable decrease in financial and human resources for many years. 
Yours sincerely on behalf of all authors,

Orwa Al Abdulla (the corresponding authors)

Researcher MSc.

Institute of public health and clinical nutrition, University of Eastern Finland UEF.

P.O. Box: 1627, FIN-70211 Kuopio, Finland

Yliopistonranta $1 \mathrm{C}$, Canthia Building, B wing.

Email: orwaa@uef.fi 


\title{
Simulation of the Progression of the COVID-19 Disease in Northwest Syria Using Basic and Adjusted SIR Model
}

\author{
Al Abdulla Orwa ${ }^{1}$, Kallström Agneta ${ }^{2}$, Kauhanen Jussi ${ }^{3}$, Camilo Valderrama \\ ${ }^{1,2,3}$ University of Eastern Finland, Institute of Public Health and Clinical Nutrition, P.O. Box \\ 1627, 70211 Kuopio, Finland.
}

Corresponding author's complete information: Name: Al Abdulla Orwa. Address: The University of Eastern Finland - Institute of Public Health and Clinical Nutrition - Faculty of Health Sciences - P.O. box 1627. FI-70211 Kuopio, Finland. orwaa@uef.fi

ORCID

Orwa Al Abdulla: https://orcid.org/0000-0002-2294-0429

Agneta Kallström: http://orcid.org/0000-0002-5442-3709

Jussi Kauhanen: https://orcid.org/0000-0003-1426-0199

\begin{abstract}
Abbreviations:
COVID-19 Community Treatment Centers (CCTCs), Early Warning, Alert, and Response Network (EWARN), Government of Syria (GoS), Intensive Care Unit (ICU), Internally Displaced Persons (IDPs), Northwest Syria (NWS), Ordinary Differential Equations (ODE), Polymerase Chain Reaction (PCR), Preparedness and Response Plan (PRP), Susceptible S, Infectious, and Removed $\mathrm{R}$ cases (SIR)
\end{abstract}

\section{1- Abstract}

Background: Syria has been experienced an armed conflict since 2011. At the time of writing, Northwest Syria is outside governmental control and facing the challenges of the COVID-19 pandemic. In this research, we studied the progression of the COVID19 pandemic in northwest Syria. We studied the impact of wearing facial masks and discussed the results compared to the existing figures and facts.

Methods: Based on available data and using the basic and adjusted SIR model, we estimated the value of the basic reproduction number $\left(R_{0}\right)$ which gives an initial 
prediction of the disease progression. We studied the disease progression for one year (from July 2020 to July 2021) and simulated using the basic and adjusted SIR models.

Results: We estimated that the $\mathrm{R}_{0}$ for 2019-nCOV was 2.38, and the resulted figures were overestimated compared to the reported numbers and data concerning the COVID-19 pandemic. However, when adjusting the model by a preventive measure (in this case, wearing face masks), the results were significantly less and closer to the actual reported numbers.

Conclusions: Hospital utilization throughout 365 days was projected depending on the basic and adjusted SIR model. The pandemic's peak in the studied area was predicted to arise in December 2020. The expected number of cases to be infected and admitted to hospitals and ICU in 365 days was 633636, 1901, and between 1141 and 2090, accordingly.

Keywords: COVID-19, coronavirus, SIR model, pandemic, Northwest Syria, emergency, humanitarian, conflict

\section{2- Introduction}

Pounding with limited information and under extreme pressures on the healthcare system since late 2019, the world has been facing the rapid spreading of a novel viral infection, Coronavirus disease (COVID-19), provoked by a new strain of coronavirus, severe acute respiratory syndrome coronavirus 2 (SARS-COV-2). The World Health Organization (WHO) declared a pandemic on 12 March 2020 [1].

The first COVID-19 case in Northwest Syria (NWS) was reported as of July 9, 2020 [2]. NWS refers to the geographical areas controlled by i) the opposition armed groups allied with the Government of Turkey in northern Aleppo, and ii) the Syrian Salvation Government in western Aleppo and Idleb, which is closely affiliated with Hayat Tahrir al-Sham [3].

As of March 2020, the Government of Syria (GoS) controlled more than 60\% of Syria [4]. It is estimated that more than three million people are in Idleb governorate, about 1.5 million of whom were internally displaced persons (IDPs) from other governorates and districts. Along with the deterioration of the humanitarian conditions, and by late February 2020, around 940,000 persons displaced from their communities, which were 
controlled by the GoS, towards and within Idleb governorate and northern and western Aleppo [5]. The resilience of 4.1 million people living in NWS has been eroded by the prolonged crisis [6]. Governance varies widely across Syria, both within and outside of government-controlled areas.

The health system in NWS has been suffering enormous challenges during the conflict. With many factors weakening its capacities, such as the presence of more than 2.8 million displaced persons, overcrowding and high density of population, and poverty [7].

Attacks against health infrastructure, loss of life, and massive waves of displacements have worsened the humanitarian situation in NWS [8]. Along with the collapse of the health care system, restricted humanitarian access, and overcrowding in IDPs sites, the humanitarian situation in NWS continues to dire, and the number of people in need of aid continues to increase [9]. With the high density of the IDPs in camps, economic collapse, and the lack of sources, many experts and researchers predicted an increased transmission risk, resulting in catastrophic figures overwhelming the ramshackle humanitarian situation in NWS [10]. many studies anticipated that the health system in NWS would not hold for long when the SARS-COV-2 pandemic starts to invade the region [7]

From public understanding to policy legislation, much depends on the data determined by the epidemic progression models that to be interpreted into actionable policies [11]. Epidemiological modeling is a practical approach to simulate disease dynamics. Multiple mathematical models have been used in the literature to understand the epidemiological characters of pandemics [12]. The most common approach to predict epidemic development is the basic SIR model, which is compartmental models of susceptible (S), infectious (I), and removed (recovered and death) (R) cases. This model is composed of a system of differential equations used to predict the dynamics of an epidemic based on predefined parameters, such as the transmission and removal rates [13]. The transmission rate of the disease is significant compared to other types of coronavirus [14]. SARS-COV-2 is described to be very contagious. In fact, COVID-19 is two to three times more contagious than influenza, and infected individuals, even if they are asymptomatic, can transmit the disease to susceptible individuals [15]. The paper explores the progression of COVID-19 disease in NWS over 365 days (from July 9, 2020, when the first COVID-19 case in NWS was confirmed, until July 8, 2021) 
employing SIR model. Syria has been announced as a disaster area in 2011 [16], since when there has been a collapse in the health system [17].

Based on SIR model, the study provides an understanding of the progress of the COVID-19 pandemic in NWS and required case management resources (hospitals and Intensive Care Units ICU). The research contributes to the literature of simulating the dynamics of the COVID-19 pandemic, particularly in a conflict emergency setting Syria. The ultimate objective of this study, besides the added value to the pool of relevant studies, is to provide evidence-based results for the decision-makers, including humanitarian actors, authorities, UN agencies, and donors, to rationally utilize the resources available for COVID-19 response and subsequently, not losing sight of other life-saving services in the conflict-affected region of NWS.

While the number of confirmed COVID-19 cases and deaths has been dramatically increasing globally [18], the figures from NWS might be slightly different. This difference in figures is attributed to various factors that should be investigated more in detail. As a result of the Preparedness and Response Plan (PRP) for COVID-19 in NWS, multiple COVID-19 Community Treatment Centers (CTCCs) and hospitals were established in the area. As of December 15, there are seven hospitals dedicated for COVID-19 cases admission in NWS, with a total capacity of 670 beds and 197 ICU beds [19] [33]. The method of blood sample collection from suspected individuals was, to some extent, explained in the PRP. The blood samples are collected by nurses from the COVID-19 Community Treatment Centers CCTCs and hospitals where susceptible subjects could be detected. Thus, people seeking PCR tests are referred to the nearest CCTC or hospital [20]. NWS Early Warning, Alert, and Response Network (EWARN) relayed that the total number of PCR tests from July 9 to December 15, 2020, was 65637, along with a total of 18949 confirmed SARS-COV-2 cases [21]. It is evident from figure (1) that the more PCR tests, the more positive cases. By referring to figure (2), it could

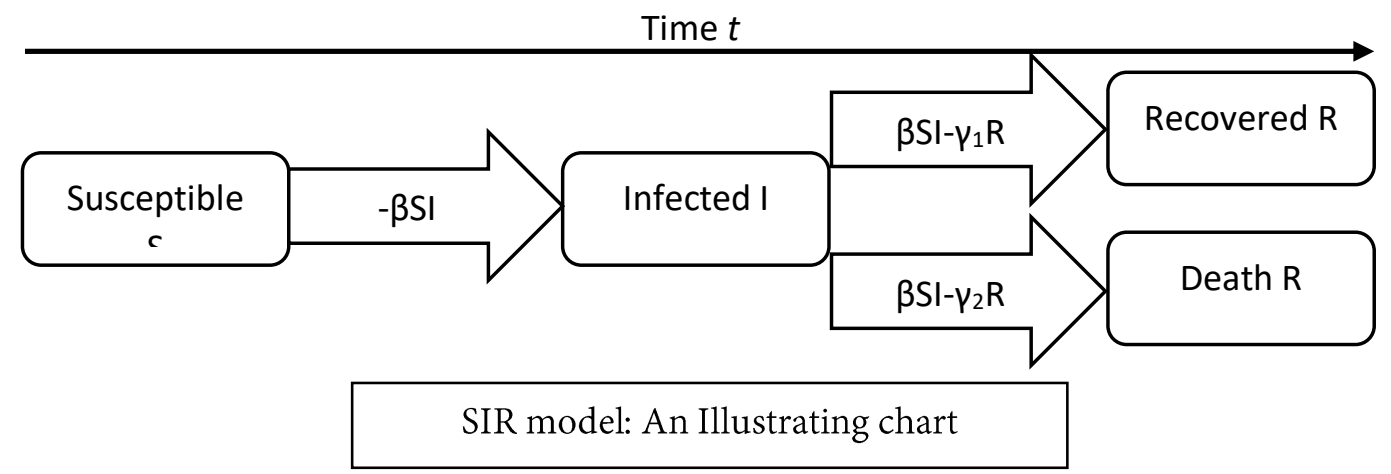


be inferred that there is a significant correlation between the number of daily PCR tests and positive cases (The value of the coefficient of determination $\mathrm{R}^{2}=0.964$ extrapolates a significant linear correlation, and $p<0.01$ ). We transformed the number of positive cases to standardized values per 100 PCR tests per day to explore the changes in the number of positive cases on a daily basis. Figure (3) illustrates a peak in the number of standardized positive tests throughout the month of November, which, to a certain extent, matches the predicted peak based on SIR models in this study (figure 4).

Figure 1: PCR tests \& daily positive cases of SARS-COV-2

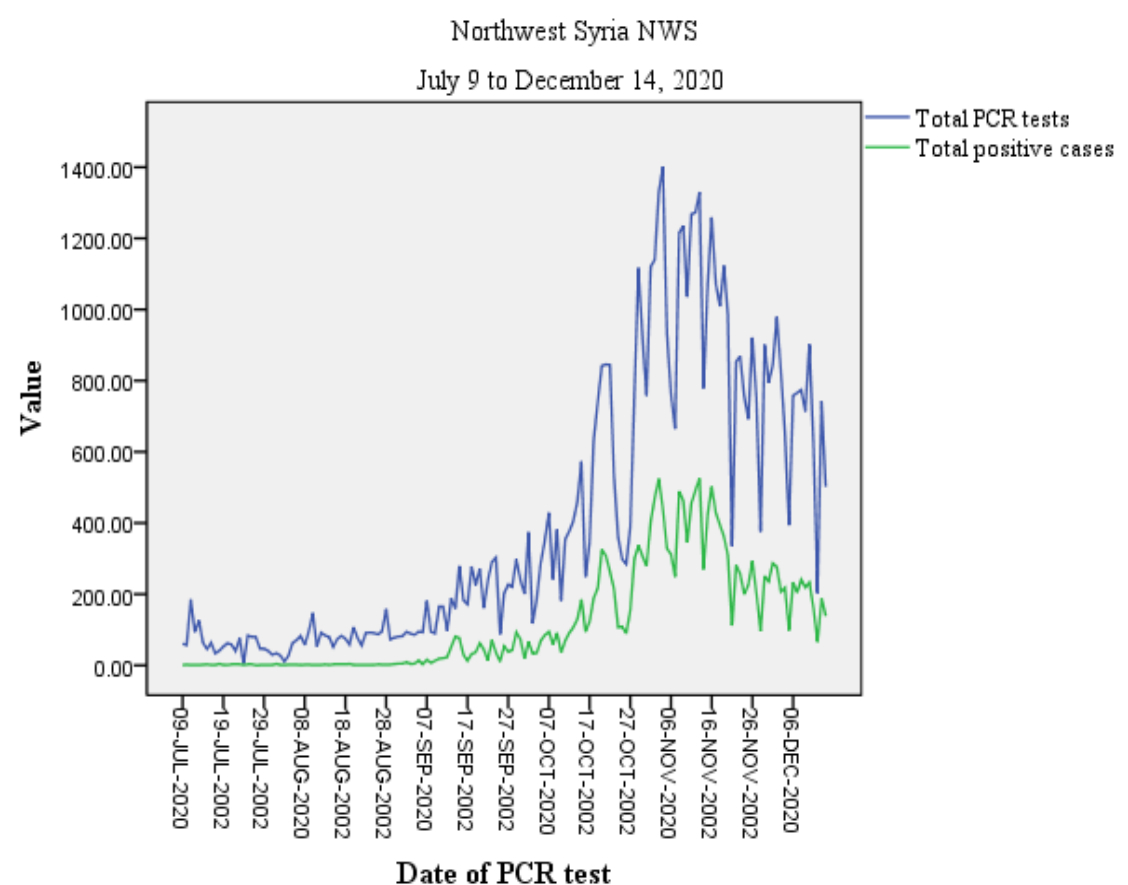

Figure 2: A scatter plot diagram of the correlation between daily COVID-19 PCR tests and positive cases
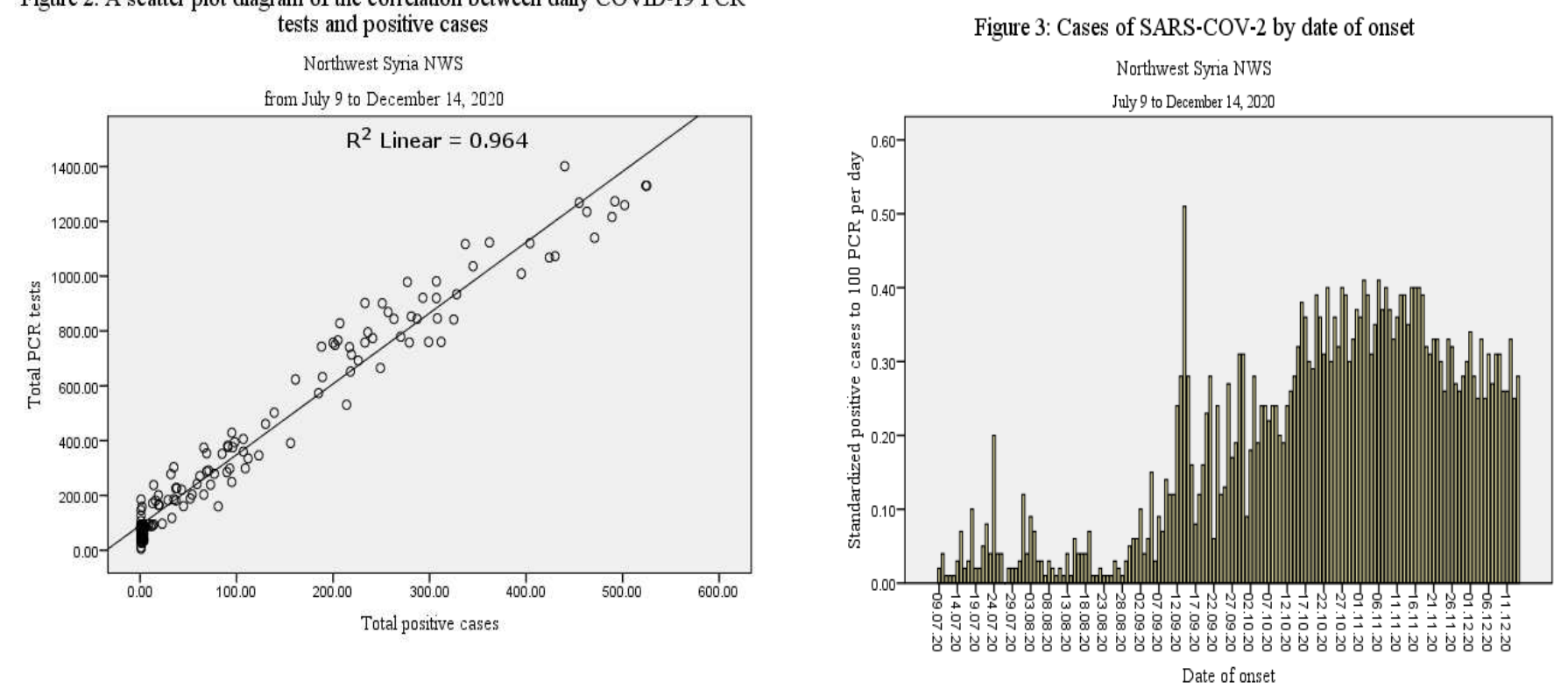


\section{Materials and Methods}

\subsection{Differential equation and basic SIR model}

The protective measures against COVID-19 are the main control measures to limit disease spread when no vaccination is available [22]. SIR epidemic disease model was utilized in this study to predict and understand the spread of COVID-19 in NWS applying Ordinary Differential Equations ODE:

$$
\begin{gathered}
\frac{d(\mathrm{~S})}{d(t)}=-\beta S I(\mathbf{1}) \\
\frac{d(\mathrm{I})}{d(t)}=\beta S I-\gamma I(2) \\
\frac{d(\mathrm{R})}{d(t)}=\gamma I(3)
\end{gathered}
$$

Based on the SIR epidemic model, the population consists of three groups; suspected, infected, and removals. We donated the sizes of these subpopulations at time $t$ by $S, I$, and $R$, where:

- $S$ refers to the susceptible cases.

- I refers to the infected and exposed cases.

- $R$ refers to the removals, including recovered and death cases. $R$ for removals is different from $R_{0}$ and $R_{e}$, where the first one denotes the basic reproduction number and the second one denotes the effective reproduction number.

- $\beta$ refers to the transmission rate constant.

- $\gamma$ refers to the removal rate constant.

- $t$ refers to time.

Equations 1, 2, and 3 represent the changes in the size of $S, I$, and $R$ throughout time. The sum of $S, I$, and $R$ is the total population. We considered several assumptions to find out the values of the parameters of the ODE. The first assumption is that NWS population $N$ remains constant, and non-covid-19-related deaths and new births are not counted throughout the study timeframe. This assumption proffers the fact that $N=S+I+R(4)$, and therefore, $\frac{d(S)}{d(t)}+\frac{d(I)}{d(t)}+\frac{d(R)}{d(t)}=0$ (5). The second assumption is that the rate of increase in $I$ is due to contact between $I$ and $S$. The increase rate is constant and is referred to by $\beta(\beta>0)$, which the infection coefficient. The third assumption is related to the removal coefficient $\gamma(\gamma>0)$, which is constant and refers to the rate of recovery and death. We also assumed that everyone who recovers would gain a long-lasting immunity and not be susceptible to the disease anymore. 
Based on our assumptions, the final form of equations 1,2 and 3 became:

$$
\begin{gathered}
d(S)_{t+1}=S_{t}-\left(\beta \frac{S_{t}}{S_{0}} * I_{t}\right)(6) \\
d(I)_{t+1}=I_{t}+\left(\beta \frac{S_{t}}{S_{0}} * I_{t}\right)-\gamma I_{t}(7) \\
d(R)_{t+1}=R_{t}+\gamma I_{t}(8) \\
S_{t}=S_{0} e^{-R_{0} \frac{R_{t}-R_{0}}{N}}(9)
\end{gathered}
$$

- So refers to the number of susceptible cases on the first day of the epidemic. Normally, $S_{0}=S-1$ ( $S_{0}$ is the number of susceptible people at the initial phase of the pandemic. In the context of COVID-19 disease, the whole population is susceptible to the virus at the initial phase without extrinsic factors such as immunization or control measures) [23].

Using the ODE-derived SIR model, we predicted the progression of the COVID-19 pandemic in NWS in this study.

4.2. The basic reproductive $R_{0}$ and effective reproductive $R_{e}$ numbers

The basic reproduction ratio, $R_{0}$, is the classical epidemiological scale associated with the reproductive power of the disease. $R_{0}$ tends to be used to refer to the number of secondary infections in a population caused by one initial primary infection. In other words, if a person has a particular disease, then the $R_{0}$ value gives how many infections, on average, that person will cause, or how many individuals that person will give the disease to, within the population [24]. For the SIR model, the values of $R_{0}$ is calculated based on the equation (10)

$$
R_{0}=\beta D=\beta / \gamma(\mathbf{1 0})
$$

- $D$ is the average duration of infection and $D=1 / \gamma$, Thus $\gamma=1 / D(\mathbf{1 1})$

$$
\beta=\tau c(12)
$$

- $\tau$ : is the transmissibility rate of the disease, i.e., the probability of transmitting the disease.

- $c_{:}$is the contact rate.

In other words, the transmission rate $\beta$ is related to the infector's contact rate with susceptible subjects and the probability of transmitting the disease to them.

Regarding the value of the parameter $R_{0}$, the severity of an epidemic can be summarized into two turns: 
- $R_{0}>1$ : The epidemic increases exponentially. In other words, one infected individual infects more than one individual on average.

- $R_{0} \leq 1$ : The epidemic will not occur, and the disease will die out without affecting a large portion of the population [25].

Simulating the dynamics of an epidemic through a specific time period can be achieved by estimating the effective reproduction number, $R_{e}$. The effective reproduction number is the average number of secondary infections caused by one infection in the same period. , $R_{e}$ is a variable number that shows time-dependent variation due to the decline in susceptible subjects and the implementation of preventive and control measures. The pandemic is increasing exponentially as long as the value of $R_{e}>1$. In return, when $\mathrm{R}_{e}<1$ it means that the epidemic is dying out [26].

The equation of the effective reproductive number is given as:

$$
R_{e}=\frac{S(t)}{N} R_{0}(13), \text { where } S_{0} / N \approx 1
$$

\subsection{Growth Rate}

The spread of an epidemic disease depends on the amount of contact between individuals and the possibility of an infected person transmitting it to another person [27]. The parameter $\lambda$ is a measure of the rate at which new cases are arising. It can be a positive number (the number of new infections is increasing) or a negative number (the number of new infections decreases). The growth rate is driven by a combination of $\mathrm{R}$ - the higher the number of cases caused by each infectious individual, the faster the epidemic will grow - and the timescale over which infections occur (generation time or serial interval) [28]. The transmission dynamics of SARS-COV-2 which is attributed to two key parameters, $R_{0}$ and the serial interval $S I$ (time delay between the symptom onset of an index infector case and secondary infectee case). The high reproductive number and short serial interval deduce an exponential growth of the pandemic. In the initial phase, the epidemic commonly spread exponentially. The effective reproduction number $R_{\mathrm{e}}$ is a function of the exponential growth rate $(\lambda)$ and the serial interval [29].

$$
R_{\mathrm{e}}=e^{\lambda \mu-\frac{1}{2} \lambda^{2} \sigma^{2}}
$$

$\lambda$ is the exponential growth rate.

$\mu$ and $\sigma^{2}$ are the mean and variance, respectively, of the serial interval. 


\section{3- Results}

\subsection{Estimating the basic reproductive numbers without control measures}

The next step to simulate the progression of COVID-19 is to determine the parameters $\beta$ and $\gamma$ that best describe the current evolution of the disease. The estimation was imitated by applying the basic SIR model of Kermack and McKendrick to predict the variation in the differential equations parameter.

For COVID19, the best information on recovery speed comes from a World Health Organization study examining more than 55000 cases in China. They found that for mild illness, the time from the onset of symptoms to natural recovery is, on average, 14 days for mild cases and 6-8 weeks for severe infections [30]. These estimates were also supported in other published studies. Because $I$ is dominated by mild cases, $D=14$ days is selected in this study. Therefore, it could be said that $\gamma=\frac{1}{D}=\frac{1}{14}=0.071$.

We reviewed the data of confirmed cases due to infector-infectee contact based on data shared by EWARN in NWS during the period from July 9, 2020, when the first confirmed case appeared until December 4, 2020. The average value of $\beta$ was 0.17 ( $\mathrm{min}=$ $0.04-\max =0.28$, with $\mathrm{SD}=0.05, \mathrm{CI}: 95 \%)$. As a result, the value of $R_{0}=\frac{\beta}{\gamma}=\frac{0.17}{0.071} \approx$ 2.38. The SIR model based on the values of $\beta, \gamma$, and $\mathrm{R}_{0}$ is illustrated in figure (4).

\subsection{The impact of using face masks on the effective reproductive number}

COVID-19 has a very high infectivity rate. Two modes of transmission exist: direct and indirect. The transmission via aerosols and droplets is the primary direct mode. In order to control the spread of the virus, it is imperative to reduce human-to-human contact, disinfection of day-to-day objects, and proper self-hygiene (washing hands regularly, proper coughing and sneezing techniques, and use of face masks). Social distancing plays a crucial role in reducing transmission [31]. According to the figures outlined on the COVID-19 response tracking dashboard, Face masks are widely available nowadays in NWS [32]. In this study, we addressed the impact of using face masks on the spread of the virus by investigating how the value of $R_{\mathrm{e}}$ could be changed due to face maskwearing $\left(R_{\alpha}\right.$ : The adjusted value of $\left.R_{e}\right)$. In an evidence review study, it was found that wearing masks reduces the effective reproduction number by a factor $\delta=\left(1-e \rho_{m}\right)^{2}$, where $e$ is the efficacy of trapping viral particles inside the mask, and $\rho_{m}$ is the 
percentage of the population that wears masks [33]. Thus, it could be concluded that $R_{\alpha}=R_{e} \delta(15)$.

Studies tackling the efficiency of the preventive measures against SARS-COV-2 virus are still scarce, according to a literature review research [34]. In this research, fabric and surgical mask performance was evaluated based on their filtration efficiency and mask pressure drop. The filtration efficiency reflects the mask's ability to filter particulates and microorganisms with a cut-off point of $0.072 \mu \mathrm{m}$ (assuming that the size of the SARS-COV-2 virus was $0.09 \mu \mathrm{m}$ [35]. The pressure drop reflects how comfortable the mask is. According to a recent assessment by REACH in NWS, less than $30 \%$ of the population uses face masks [36]. Nevertheless, we took into account other factors that could reduce the mask efficiency (pressure drop, the bias in the assessment results, improper using of the mask, those who claimed using masks do not use it continuously when they are in touch with other people). Therefore, the filtration efficiency value was adopted to be $\rho_{m}=0.2$ as an average. Thus, $\delta \approx 0.92$. As a magnitude of the impact of wearing face masks rendering the virus spread, the value of $R_{\alpha}$ will decline from 2.38 to 2.19 and reach its minimum value (0.26) by April 2021. Considering that $R_{e}=R_{0}$ at the initial phase of the epidemic when everyone in a population is susceptible [37], and positing that the adherence to face masks is constant and started from the beginning of the epidemic, and recalling the equation (10), $\beta=R_{0} * \gamma$, we assumed that $R_{\alpha}=$

Figure 4: Basic SIR model

Northwest Syria NWS

from July 9,2020 to July 8, 2021

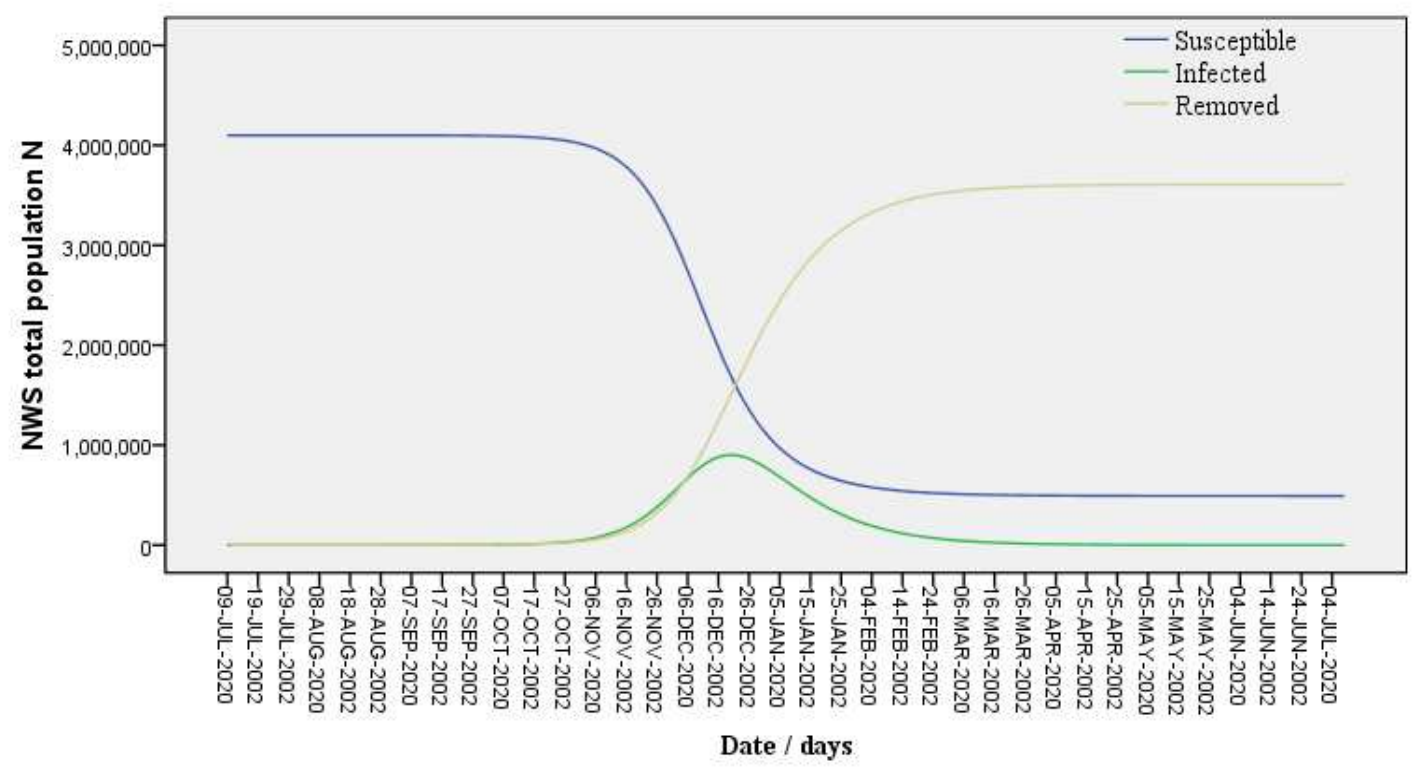


$\mathrm{R}_{0 \alpha}$ ( $R_{0 \alpha}$ is the adjusted basic reproductive number), and adjusted the value of $\beta$ to $\beta_{\alpha}$ $\approx 0.16$. The adjusted SIR model was predicted on this basis, as depicted in figure (5).

Based on the modified SIR model, the total number of people in NWS who will get infected with SARS-COV-2 from July 9, 2020, until July 8, 2021, is $\sum_{d=1}^{d=365} I=633636$, where $d$ denotes the year days since the detection of the first confirmed COVID-19 case.

5.3. Pandemic peak, growth rate, and adjusted growth rate of COVID-19 disease in NWS.

In fact, ample scientific evidence and information have been provided about serial interval for COVID-19 using multiple methods. After reviewing three meta-analysis studies, tackling the serial interval SI for COVID-19 globally, and with 95\% CI, we adopted a value of 5.2 days for SI, and 4 days for the standard deviation SD [38] [39] [40]. Recalling the equation (14): $R_{e}=e^{\lambda \mu-\frac{1}{2} \lambda^{2} \sigma^{2}}$, we found that when $R_{e}=2.38$ in July 2020, the value of $\lambda$ was 0.22 , which surmises an exponential growth rate of the disease. The value of $\lambda$ declines to reach (0) in the middle of December and becomes negative afterward. When $R_{0}=2.38$ and $\lambda \approx 0.22$, it is expected that the peak of the disease in NWS occurred on December 20. When we adopted the value $R_{\alpha}=2.19$, we found that the value of $\lambda$ declined to be $\lambda_{\alpha}=0.20$. Although this difference did not significantly change the period of the predicted peak (21 December for the adjusted model), it noticeably changed the outputs of SIR model and reduced the severity of the pandemic (figures $4 \& 5$ ). While the number of infected cases on the peak day based on the basic model is 902580, it is 156843 cases based on the purpose-built model (figure 6).

\subsection{Projecting hospital utilization during the COVID-19 pandemic in NWS}

There are no available data from NWS about the length of stay LoS of hospitalized and ICU cases. Based on EWARN data, about 97\% of coronavirus cases in NWS are not severe [41]. Due to the limited capacity in terms of PCR tests, the method of samples collection, and the fact that many suspected cases could not be covered by the tests, we did not calculate the percentage of hospitalized patients and ICU patients from the total confirmed cases during the date of data extraction (The total confirmed cases in NWS from November $1^{\text {st }}$ until December $15^{\text {th }}$ was 13113) [12]. Therefore, we relied on the adjusted SIR model to estimate the percentages of cases that need hospitalization and intensive care. We studied the number of cases admitted to hospitals and ICU throughout three periods of 14 days $(D=1 / \gamma)$, from November 1 until December 12, 
2020, and compared the number of infected cases in consonance with the adjusted SIR model with the number of hospitals and ICU admitted cases. The anticipated number of daily cases based on the adjusted SIR model versus the actual number of hospital and ICU admitted cases is delineated in table (1).

Figure 5: Adjusted SIR model (R0a=2.19)

Northwest Syria NWS

from July 9, 2020 to July 8, 2021

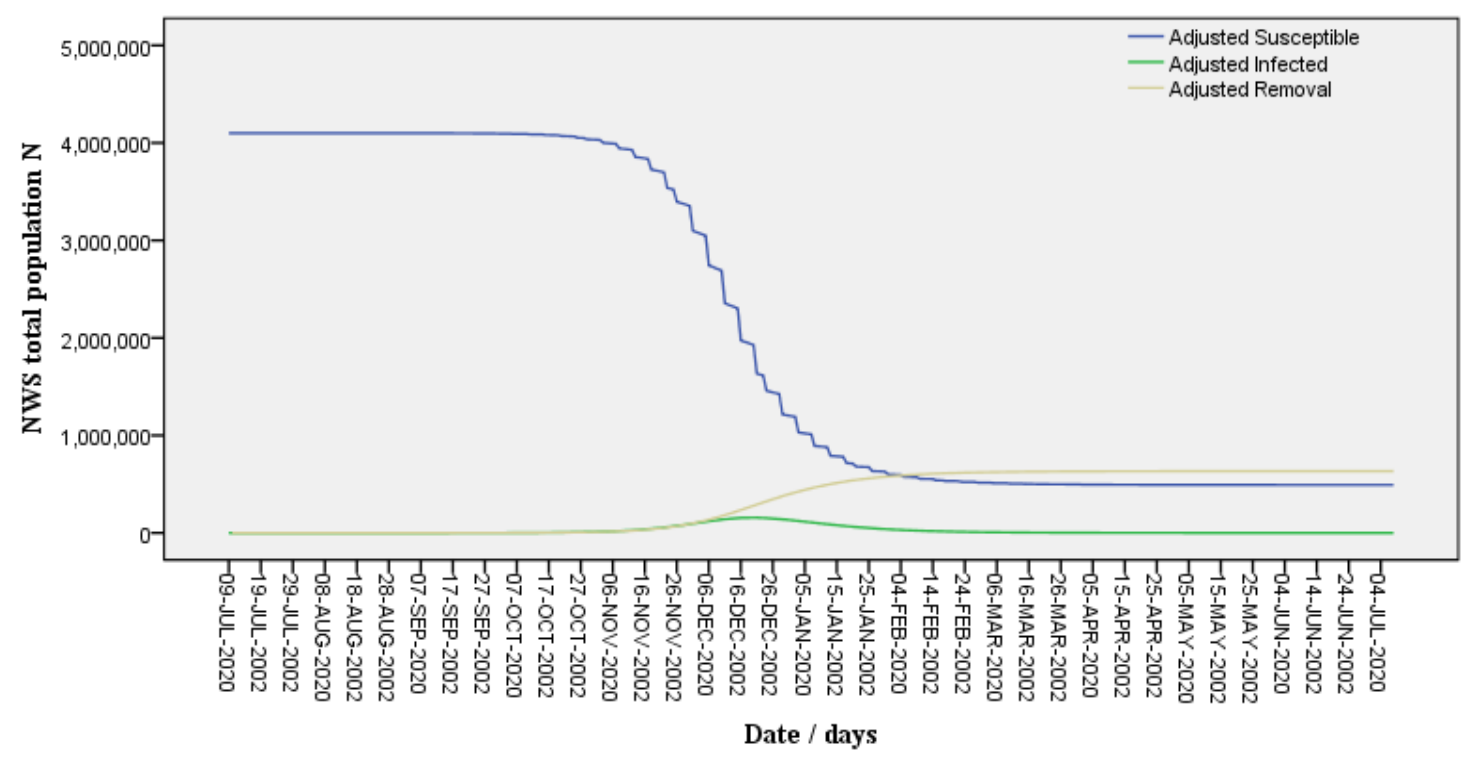

Figure 6: Infected cases based on the adjusted SIR model Northwest Syria NWS

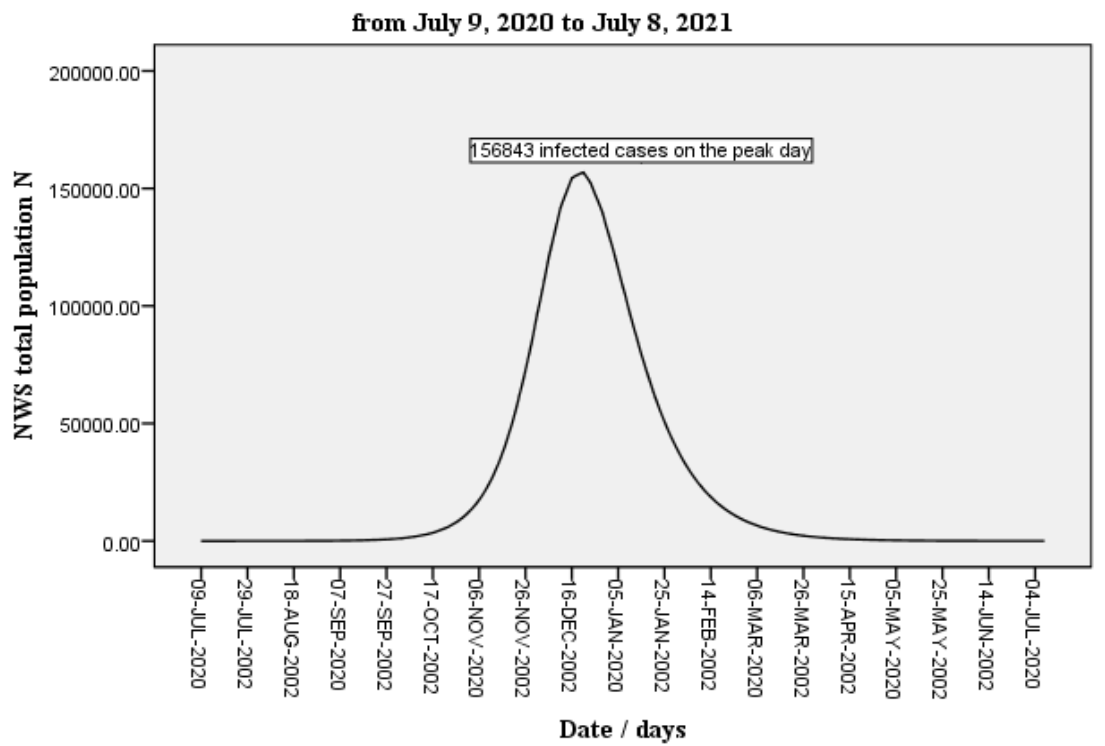


Table 1: Predicted admission rates of COVID-19 cases to hospitals and ICU in NWS based on the total number of daily cases based on the adjusted SIR model

\begin{tabular}{|l|l|l|l|l|l|}
\hline Period & $\begin{array}{l}\text { Total number of } \\
\text { daily cases } \\
\text { (Adjusted SIR } \\
\text { model) }\end{array}$ & $\begin{array}{l}\text { Number of } \\
\text { Actual cases } \\
\text { admitted to } \\
\text { hospitals }\end{array}$ & $\begin{array}{l}\text { \% of actual } \\
\text { cases } \\
\text { admitted to } \\
\text { hospitals out } \\
\text { of the total } \\
\text { daily cases }\end{array}$ & $\begin{array}{l}\text { Number of } \\
\text { Actual cases } \\
\text { admitted to } \\
\text { ICU }\end{array}$ & $\begin{array}{l}\text { \% of actual } \\
\text { cases } \\
\text { admitted to } \\
\text { ICU out of } \\
\text { the total } \\
\text { daily cases }\end{array}$ \\
\hline $\begin{array}{l}1 / 11- \\
14 / 11\end{array}$ & 40381 & 236 & $0.6 \%$ & 134 & $0.33 \%$ \\
\hline $\begin{array}{l}15 / 11- \\
28 / 11\end{array}$ & 101916 & 227 & $0.2 \%$ & 148 & $0.15 \%$ \\
\hline $\begin{array}{l}29 / 11- \\
12 / 12\end{array}$ & 175020 & 185 & $0.1 \%$ & 111 & $0.06 \%$ \\
\hline $\begin{array}{l}\text { Total/ } \\
\text { Average }\end{array}$ & 317317 & 648 & $0.3 \%$ & 393 & $0.18 \%$ \\
\hline
\end{tabular}

It is anticipated that about $0.3 \%$ and $0.18 \%$ of COVID-19 cases in NWS might need hospitalization and ICU beds, respectively. Based on the total anticipated number of patients who will get infected with SARS-COV-2 virus (633636). The predicted number of patients who need hospitalization and ICU admission from July 9, 2020, until July 8 , 2021 , is elaborated in table (2).

Table 2: Predicted number of COVID-19 cases that need hospital and ICU admission in NWS from June 9, 2020, until June 8, 2021, based on the adjusted SIR model

\begin{tabular}{|l|l|l|l|l|}
\hline $\begin{array}{l}\text { Predicted number } \\
\text { of COVID-19 cases } \\
\text { from July 9, 2020, } \\
\text { until July 8, 2021 } \\
\text { (Adjusted SIR } \\
\text { model) }\end{array}$ & $\begin{array}{l}\text { \% of actual cases } \\
\text { admitted to } \\
\text { hospitals out of } \\
\text { the total daily } \\
\text { cases }\end{array}$ & $\begin{array}{l}\text { Predicted } \\
\text { number of } \\
\text { cases that need } \\
\text { hospital } \\
\text { admission }\end{array}$ & $\begin{array}{l}\text { \% of actual cases } \\
\text { admitted to ICU } \\
\text { out of the total } \\
\text { daily cases }\end{array}$ & $\begin{array}{l}\text { Predicted } \\
\text { number of } \\
\text { cases that need } \\
\text { ICU admission }\end{array}$ \\
\hline 633636 & $0.3 \%$ & 1901 & $0.18 \%$ & $\begin{array}{l}1141 \text { (2090 if the } \\
\text { percentage of ICU } \\
\text { admitted cases is } \\
0.33 \%)\end{array}$ \\
\hline
\end{tabular}

The expected numbers of hospitalization and ICU admitted cases throughout 365 days were projected using the customized SIR model to understand their load on the current capacity of COVID-19 hospitals in NWS (Figure 7). 
To assess the pandemic impact on the health system in NWS, we used basic equations to calculate the number of required hospital and ICU beds after calculating the total expected number of SARS-COV-2 patients.

$$
\text { Number of beds needed }=\frac{\text { bed days }}{365 \text { days }}(\mathbf{1 6})
$$

The value of bed days was calculated using the equation.

$$
\text { Bed days = average number of patients } X \text { average length of stay (17) }
$$

We adopted systematic-reviewed data because the information about the length of stay for hospitalized and ICU admitted COVID-19 cases in NWS is limited and not reliable. The adopted values of LoS for hospitalized and ICU cases were 15.3 days and 8.8 days, respectively [42]. The predicted number of severe cases (needing hospitalization and ICU) was utilized as an average number of patients. As a result, we found out that the bed days for cases that need hospitalization for 365 days is 29085.3 days and for cases that need ICU admission is 10040.8 days. Accordingly, the number of hospital beds needed is 80 , and for the required ICU beds is 28 . However, due to the lack of information on the DHIS platform for NWS, we took the average of ICU admitted patients as $0.33 \%$, as it seems to be in line with recently reported numbers of ICU admissions. The predicted number of ICU beds needed, in this case, became 51 .

Figure 7: Flow of COVID-19 cases that need hospital and ICU admission based on the adjusted SIR model

Northwest Syria NWS July 9, 2020 until July 8, 2021

July 9, 2020 until July 8, 2021

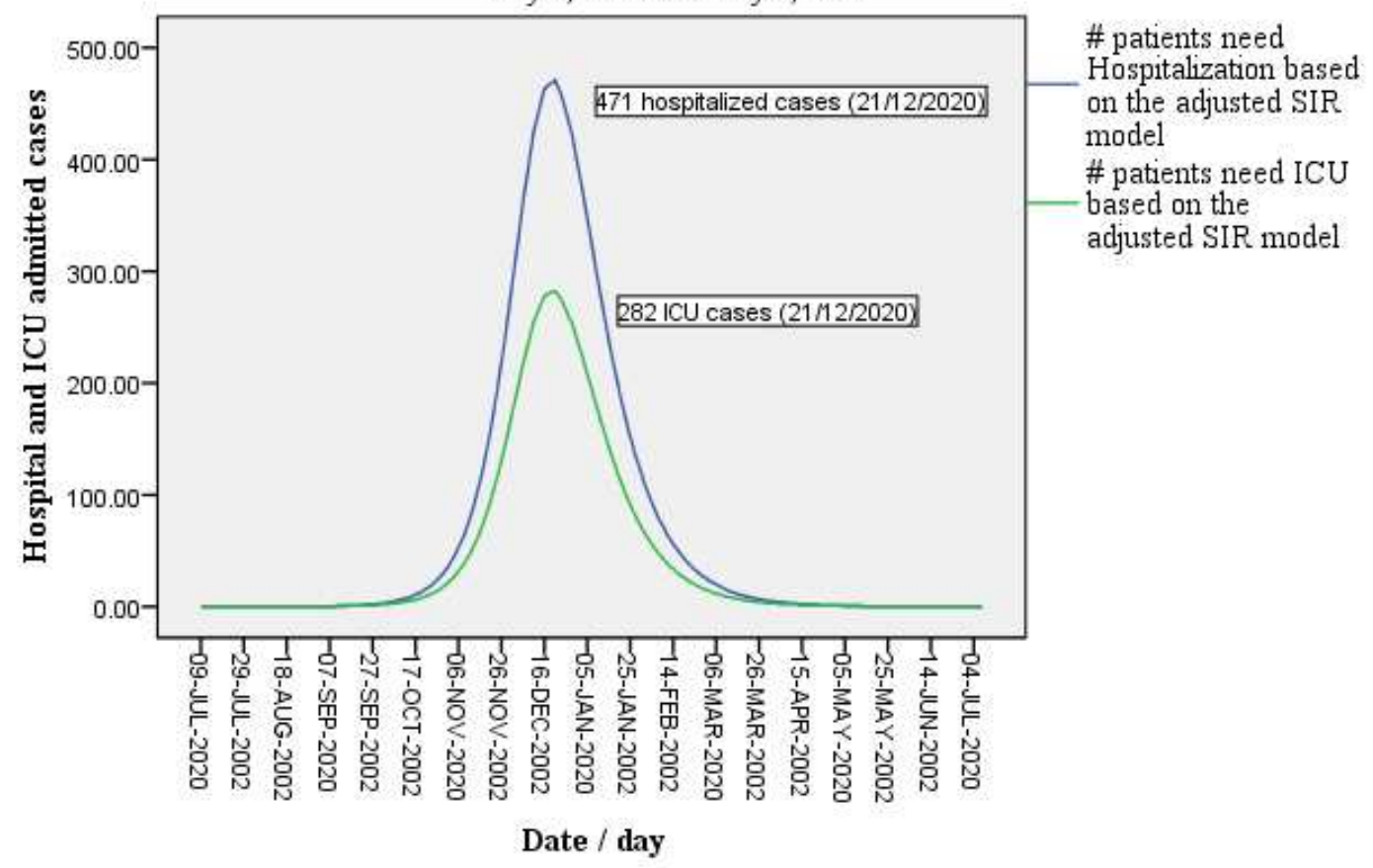




\section{4- Discussion}

The first case of SARS-COV-2 in NWS was confirmed on July 9 for a doctor in a hospital situated near the Syrian-Turkish border [43]. The date of the first case appearance was late compared to other countries. This delay could be attributed to the aforementioned political conditions besides the limited access and cross-border closure for the past few years [44]. Consequently, the contact rate with cases from outside the region was minimal, resulting in a delayed appearance of the first cases.

Suppositionally, if the initial value obtained from exponential fitting is positive with an increased number of cases over time, the growth is exponential. In confirmation of that, it is concluded earlier that SARS-COV-2 virus typically spreads exponentially in the absence of artificial immunization and preventive measures [18]. Without the COVID19 PRP and relevant implementation, the significant value of $\lambda$ would have undoubtfully overwhelmed the capacity of the fragile healthcare system in NWS, highlighting the scarcity of human and financial resources. In fact, digital technologies, data, and crossborder e-health services like telemedicine have become essential support mechanisms in response to the pandemic. Allowing temporary movement of health professionals could also help alleviate capacity constraints on the health systems [45].

In this study, the progress of the COVID-19 pandemic in NWS was researched to reveal its epidemiological characteristics in a prolonged emergency-affected region, Syria.

The setup we used in this study bears a close resemblance to many other approaches that highlighted COVID-19 dynamics. Nonetheless, dissimilarly, the methodology of this research appraises one of the most widely followed preventive measures (face mask using), which would significantly change the disease spread and development. On this basis, the SIR model for NWS has been customized and put forward, and on which we relied to predict hospital utilization during the COVID-19 pandemic in NWS. This research generates noteworthy interest in terms of outbreak simulation methods by tailoring the SIR model to a confounding factor.

During the literature review, we noticed that quite a number of articles and papers researching COVID-19 progression in different countries based on SIR model had been published. However, not all of them addressed preventive measures and how they influence disease development. Preventive measures like face masks wearing, lockdown, and social distancing reduce both transmissibility and contact rates, which will, consequently, reduce the values of $\beta, R_{e}$, and $R_{0}$. Most of the published papers concerning the COVID-19 pandemic relied on the value of $R_{0}$ to utilize SIR model without further adjustment to the values of $\beta$ or $R_{e}$. The higher the value of $R_{0}$, the 
more severe impact of the pandemic based on SIR model [46], and thus, the extracted results and information expected severe outcomes that seem overestimated and divorced from reality, and, as a result, a large proportion of resources that would be utilized might be unnecessary, and humanitarian settings are subjected to this fact [47]. In consonance with these facts, we found that the number of infected cases during the peak day was 902580 pursuant to the basic SIR model. However, based on the adjusted SIR model, the number of infected cases during the peak day was 156843, which seems more relevant to the reported data from NWS, and incomparably less than the same number resulted from the basic SIR model. Furthermore, the number of patients who needs hospital and ICU admission on the peak day was 2708 and 1625, respectively, without customization. These numbers, nonetheless, enormously decreased after adjusting the model and predicting the hospitalization and ICU admission rates, as elucidated explained in section 3.4. Moreover, when reviewing the literature, we noticed that most of the studies about COVID-19 came from China, and their results have been adopted by many other studies to predict and understand the disease progression in other countries. Resultantly, these studies overestimated the severity of the disease on the health system, bearing in mind that the response to the disease in China was delayed until realizing the novel virus, which exaggerated the situation and increased the transmission rate before enacting prevention measures and response plan. In contrast, many other countries prepared adequately and appropriately before the appearance of the first case in these countries. Although the region of NWS is affected by a prolonged war and the health system is fragile [48], the preparation and response plan for COVID19 was drafted, and the health cluster task force was formed four months before detecting the first case in July [49].

The value of $R_{0}$ and $\lambda$ in NWS was 2.38 and $\lambda=0.22$ at the initial phase of the pandemic. Because there is no scientific basis on which we can rely to compare this value to other values of $R_{0}$ from other places. Furthermore, the value of $R_{0}$ varied from one region to another based on our revision of 34 recently published or submitted.

In annex (1), we summarized the value of $R_{0}$ in several reviewed research studies. The mean of $R_{0}$ values across the 34 reviewed studies was 3.2, and the median 2.97. Figure (8) shows a boxplot of 77 values of $R_{0}$ according to the revised studies from several countries. The value of $R_{0}$ of this study is within the Inter Quartile Range IQR of the boxplot, which is not unexpected because the modality of these studies is to a far extent similar to our study. However, the value of $R_{0 \alpha}$ of this study was below the $1^{\text {st }}$ IQR. 
Figure 8: Boxplot of 77 values of R0 according to basic SIR model from different countries

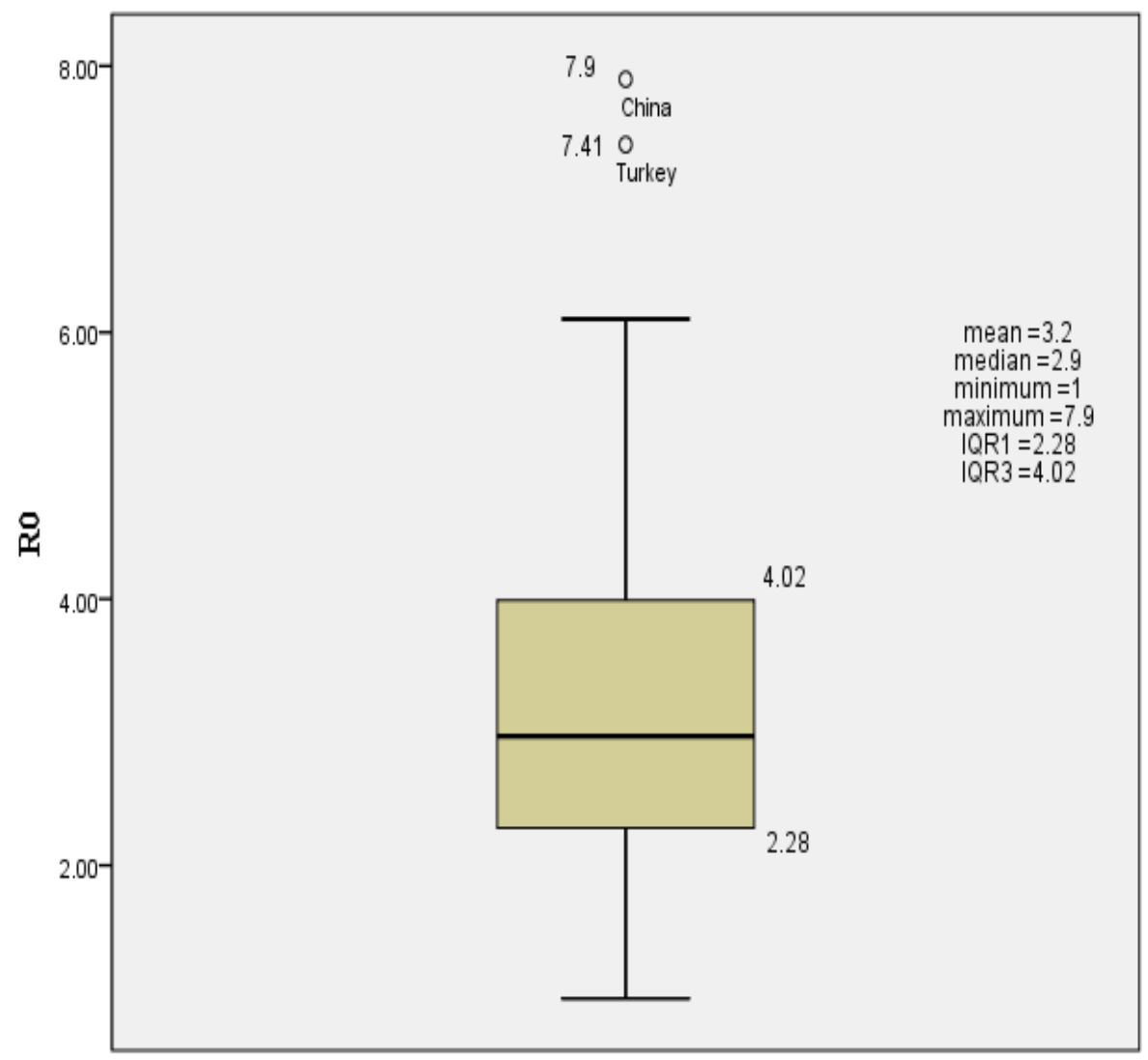

Out of the total reviewed studies, only two presented the value of $R_{0}$ in Syria without any further political or humanitarian determinations [62] [72]. The value of $R_{0}$ in these studies was 2.79 and 3.99, which is remarkably higher than the $R_{0}$ and $R_{0 \alpha}$ in this study (2.38 and 2.19, respectively).

The adjusted growth rate value is $\lambda_{\alpha}=0.20$, and relevantly, $R_{0 \alpha}=2.19$. There are enormous disparities between the outputs of the basic and adjusted SIR models. While the preliminary results of the adjusted SIR model sound acceptable and relatively close to the actual figures, the SIR model-resulted data seem overestimated and exaggerated compared to the actual figures. This statement could be verified by the current existed data and observations reported by humanitarian actors in NWS. In both models, the peak is predicted to take place between December and January. The current figures and reports are definitely more relevant to the parameters and results of the adjusted SIR model (table 3).

While there is a slight difference between the actual and predicted figures based on the adjusted SIR model, the variation is tremendous when considering the model without modification. Apart from the discordance between the findings of this study and the 
actual counterpart numbers, the results are confirmation of a conclusion raised by John Hopkins University experts in a webinar held in October 2020. The conclusion states that many studies and assessments have exaggerated and overestimated COVID-19 transmission and impact in humanitarian settings [47].

Table 3: Actual and predicted data based on the basic and adjusted SIR model

\begin{tabular}{|c|c|c|c|}
\hline Predicted data and figures & Basic SIR model & $\begin{array}{l}\text { Adjusted SIR } \\
\text { model }\end{array}$ & $\begin{array}{l}\text { Actual data and } \\
\text { figures }\end{array}$ \\
\hline Total number of infected cases & $\begin{array}{l}3608441 \text { ( } 88 \% \text { of the } \\
\text { total population) }\end{array}$ & $\begin{array}{l}633636(15.45 \% \text { of } \\
\text { the total population) }\end{array}$ & $\begin{array}{l}18949[21](28.86 \% \\
\text { of the total PCR tests, } \\
\text { as of December } 15)\end{array}$ \\
\hline $\begin{array}{l}\text { Total number of the hospital- } \\
\text { admitted cases }\end{array}$ & 151537 & 1901 & $\begin{array}{l}740[19] \text { (as of } \\
\text { December 15) }\end{array}$ \\
\hline $\begin{array}{l}\text { Maximum number of ICU- } \\
\text { admitted cases from June 9, } 2020 \\
\text { until June 8, } 2021\end{array}$ & $\begin{array}{l}90922(166675 \text { when } \\
\text { ICU admission rate is } \\
0.33 \%)\end{array}$ & $\begin{array}{l}1141 \text { (2090 when } \\
\text { ICU admission rate is } \\
0.33 \%)\end{array}$ & $\begin{array}{l}465[19] \text { (as of } \\
\text { December 15) }\end{array}$ \\
\hline $\begin{array}{l}\text { Maximum number of infected } \\
\text { cases during the peak day }\end{array}$ & 902580 & 156843 & NA \\
\hline $\begin{array}{l}\text { Maximum number of hospitals } \\
\text { admitted cases during the peak } \\
\text { day }\end{array}$ & 2708 & 471 & $\begin{array}{l}98 \text { [19] (the highest } \\
\text { admitted cases in } \\
\text { hospitals on one day, } \\
\text { between } 10 \text { and } 20 \\
\text { Dec) }\end{array}$ \\
\hline $\begin{array}{l}\text { Maximum number of ICU } \\
\text { admitted cases during the peak } \\
\text { day }\end{array}$ & 1625 & 282 & $\begin{array}{l}89 \text { [19] (the highest } \\
\text { admitted cases in ICU } \\
\text { on one day, between } \\
10 \text { and } 20 \text { Dec) }\end{array}$ \\
\hline $\begin{array}{l}\text { Number of beds needed/available } \\
\text { for hospitals }\end{array}$ & 6352 (needed) & 80 (needed) & $\begin{array}{l}670 \text { [32] (available as } \\
\text { of } 15 \mathrm{Dec} \text { ) }\end{array}$ \\
\hline $\begin{array}{l}\text { Number of beds needed/available } \\
\text { for ICU }\end{array}$ & 2192 (needed) & $\begin{array}{l}52 \text { (needed, when the } \\
\text { ICU admission rate is } \\
0.33 \% \text { ) }\end{array}$ & $\begin{array}{l}212[32] \text { (available as } \\
\text { of } 15 \text { Dec) }\end{array}$ \\
\hline
\end{tabular}

\section{5- Recommendations}

a. Support and improve the current DHIS for the COVID-19 epidemic in NWS to immediately reflect the accurate data from the COVID-19 health facilities in NWS. Stakeholders who are engaged in COVID-19 response must be committed to sharing data with the DHIS unit regularly using a unified health information system.

b. The number of admissions does not represent only the confirmed cases. Instead, it represents suspected, probable, and confirmed cases [19]. As a result, the reported impact of the disease on the health system might be overestimated. Applicable 
admission and discharge protocols are therefore of critical importance for efficient utilization of available resources.

c. Re-estimate the appeal for NWS COVID-19 strategic PRP, including but not limited to required financial resources for the different scopes of response, deployment of human resources, actors, and stakeholders' commitment to the plan, and keeping abreast of global and local changes and adaptability to cope with them.

d. To avoid any potential deviation -due to bias- from the actual future and current figures, the projected hospital utilization rates could be increased by $10 \%$ or $20 \%$.

e. In an area affected by a protracted armed conflict, NWS, where the available resources are scarce, it is necessary to mention that, by completing this research, there was only one actor performing PCR tests with a capacity that does not exceed 1700 tests per day [2]. The limited laboratory capacity contends that not all COVID19 suspected cases could be covered by these tests, which means that not all positive cases had been recorded.

\section{6- Annexes}

\begin{tabular}{|l|l|l|l|}
\hline \multicolumn{4}{|l|}{ Annex 1: R0 value according to COVID-19-related studies } \\
\hline No & \multicolumn{1}{|l|}{$R_{0}$} & Place & First author \\
\hline 1 & 2.2 & Wuhan - China & Li Q [50] \\
\hline 2 & 2.6 & China & Zhao S [51] \\
\hline 3 & 4.6 & Hubei - China & Anastassopoulou C [52] \\
\hline 4 & 4.7 & Wuhan - China & Zhao S [53] \\
\hline 5 & 1.52 & China & Zhao S [53] \\
\hline 6 & 2.79 & China & Dur-e Ahmad M [54] \\
\hline 7 & 5.2 & Wuhan - China & Mizumoto K [55] \\
\hline 8 & 7.9 & Wuhan - China & Zhu H [56] \\
\hline 9 & 5.06 & Heilongjiang - China & Sun T [57] \\
\hline 10 & 3.2 & Wuhan - China & Davies N [58] \\
\hline 11 & 2.7 & Wuhan - China & Wang L [59] \\
\hline 12 & 2.55 & China & Aghaali M [60] \\
\hline 13 & 2.1 & Wuhan - China & Jung [61] \\
\hline 14 & 1.72 & China & Al-Raeei M [62] \\
\hline 15 & 2.24 & China & Zhao S [63] \\
\hline 16 & 3.11 & Wuhan - China & Read [64] \\
\hline 17 & 5.93 & Hubei - China & Zhao S [53] \\
\hline 18 & 2.68 & Wuhan - China & Wu J [65] \\
\hline 19 & 3.2 & Wuhan - China & Jung S [61] \\
\hline 20 & 3.15 & China & Tian H [66] \\
\hline 21 & 2.2 & Wuhan - China & Riou J [67] \\
\hline 22 & 3.58 & China & Zhao S [63] \\
\hline
\end{tabular}




\begin{tabular}{|c|c|c|c|}
\hline 23 & 2.97 & Anhui-China & Tian J [68] \\
\hline 24 & 2.6 & S. Korea & Zhuang Z [69] \\
\hline 25 & 3.2 & S. Korea & Zhuang Z [69] \\
\hline 26 & 1.78 & S. Korea & Aghaali M [60] \\
\hline 27 & 1.59 & S. Korea & $\mathrm{Xu} \mathrm{C} \mathrm{[70]}$ \\
\hline 28 & 2.6 & Japan & Kuniya T [71] \\
\hline 29 & 2.79 & Syria & Al-Raeei M [62] \\
\hline 30 & 3.99 & Syria & Rahman B [72] \\
\hline 31 & 2.37 & Africa & Musa S [29] \\
\hline 32 & 1.56 & Cameroon & Nguemdjo U [73] \\
\hline 33 & 1.00 & Nigeria & Al-Raeei M [62] \\
\hline 34 & 1.06 & Iraq & Ibrahim M [74] \\
\hline 35 & 3.5 & Iraq & Rahman B [72] \\
\hline 36 & 1.03 & Egypt & Ibrahim M [74] \\
\hline 37 & 3.47 & Qom - Iran & Aghaali M [75] \\
\hline 38 & 4.86 & Iran & Sahafizadeh E [75] \\
\hline 39 & 1.82 & Iran & Aghaali M [60] \\
\hline 40 & 4.13 & Iran & Rahman B [72] \\
\hline 41 & 2.7 & Shahroud - Iran & Khosravi A [76] \\
\hline 42 & 3.37 & Italy & Aghaali M [60] \\
\hline 43 & 3.3 & Italy & Zhuang Z [69] \\
\hline 44 & 2.3 & Italy & Zhuang Z [69] \\
\hline 45 & 2.38 & Italy & Giordano G [77] \\
\hline 46 & 4.9 & Italy & Ke R [78] \\
\hline 47 & 4.08 & Israel & Rahman B [72] \\
\hline 48 & 2.28 & Pakistan & Noreen N [79] \\
\hline 49 & 2.28 & Malaysia & Alsayed A [80] \\
\hline 50 & 5.25 & Brazil & Crokidakis N [81] \\
\hline 51 & 4.05 & Cyprus & Rahman B [72] \\
\hline 52 & 2.3 & Ontario - Canada & Tuite A [82] \\
\hline 53 & 3.8 & Belgium & Ke R [78] \\
\hline 54 & 4.4 & France & Ke R [78] \\
\hline 55 & 2.72 & France & Al-Raeei M [62] \\
\hline 56 & 4.7 & Germany & $\operatorname{Ke~R~[78]~}$ \\
\hline 57 & 3.7 & Netherlands & Ke R [78] \\
\hline 58 & 6.1 & Spain & Ke R [78] \\
\hline 59 & 3.6 & Switzerland & $\operatorname{Ke~R~[78]~}$ \\
\hline 60 & 3.9 & The United Kingdom & Ke R [78] \\
\hline 61 & 5.8 & The United States & $\operatorname{Ke~R}[78]$ \\
\hline 62 & 1.61 & The United States & Al-Raeei M [62] \\
\hline 63 & 1.29 & Russia & Al-Raeei M [62] \\
\hline 64 & 7.41 & Turkey & Rahman B [72] \\
\hline 65 & 2.7 & Kuwait & Rahman B [72] \\
\hline 66 & 3.39 & Bahrain & Rahman B [72] \\
\hline
\end{tabular}




\begin{tabular}{|l|l|l|l|}
\hline 67 & 4.18 & Qatar & Rahman B [72] \\
\hline 68 & 4.45 & Saudi Arabia & Rahman B [72] \\
\hline 69 & 2.73 & The United Emirates & Rahman B [72] \\
\hline 70 & 2.6 & Oman & Rahman B [72] \\
\hline 71 & 3.52 & Jordan & Rahman B [72] \\
\hline 72 & 3.35 & Egypt & Rahman B [72] \\
\hline 73 & 3.16 & Lebanon & Rahman B [72] \\
\hline 74 & 2.89 & Palestine & Rahman B [72] \\
\hline 75 & 1.4 & Yemen & Al-Raeei M [62] \\
\hline 76 & 1.66 & Sri Lanka & Dharmaratne S [83] \\
\hline 77 & 1.25 & India & Al-Raeei M [62] \\
\hline
\end{tabular}

\section{7- Acknowledgment}

This research was undertaken in cooperation with the Strategic Research Center SRC - Turkey, Gaziantep.

\section{8- References}

1. Bordehore C, Herrador Z, Fonfría E, Navarro M. Understanding COVID-19 spreading through simulation modeling and scenarios comparison: preliminary results. MedRvix. 2020; Preprint article. doi:10.1101/2020.03.30.20047043.

2. Douedari Y, Alhaffar M, Al-Twaish M et al. "Ten years of war! You expect people to fear a 'germ'?": A qualitative study of initial perceptions and responses to the COVID-19 pandemic among displaced communities in opposition-controlled northwest Syria. Journal of Migration and Health. 2020;1-2:100021. doi:10.1016/j.jmh.2020.100021

3. E. Humud C, M. Blanchard C. Armed Conflict In Syria: Overview And U.S. Response. Washington, D.C.: Congressional Research Service; 2020. https://fas.org/sgp/crs/mideast/RL33487.pdf.

4. Saban N. Analysis of Territorial Control in Northwestern Syria and the HTS's Role. Center of Middle Eastern Studies. 2020;270. ISBN:978-625-7219-10-5

5. André B. COVID-19 And The Syrian Conflict: Implications For International Actors And Their Strategies. Beirut: Friedrich-Ebert-Stiftung; $2020 . \quad$ http://library.fes.de/pdffiles/bueros/beirut/16338.pdf.

6. Bdaiwi $Y$, Rayes D, Sabouni A et al. Challenges of providing healthcare worker education and training in protracted conflict: a focus on non-government controlled areas in north west Syria. Confl Health. 2020;14(1). doi:10.1186/s13031-020-00287-9

7. Fouad F, Sparrow A, Tarakji A et al. Health workers and the weaponisation of health care in Syria: a preliminary inquiry for The Lancet -American University of Beirut Commission on Syria. The Lancet. 2017;390(10111):2516-2526. doi:10.1016/s0140-6736(17)30741-9

8. Wille B, Weir R. Targeting Life in Idlib. The United States of America: Human Rights Watch; 2020:11

9. Office for the Coordination of Humanitarian Affairs. Syrian Arab Republic: Recent Developments In Northwest Syria. OCHA; 2020. https://reliefweb.int/report/syrian-arab-republic/recentdevelopments-northwest-syria-situation-report-no-20-9-september 
10. Ekzayez A, al-Khalil M, Jasiem M et al. COVID-19 response in northwest Syria: innovation and community engagement in a complex conflict. Journal of Public Health. 2020;42(3):504-509. doi:10.1093/pubmed/fdaa068

11. Kaplan E, Craft D, Wein L. Emergency response to a smallpox attack: The case for mass vaccination. Proceedings of the National Academy of Sciences. 2002;99(16):10935-10940. doi:10.1073/pnas.162282799

12. Alrasheed H, Althnian A, Kurdi H, Al-Mgren H, Alharbi S. COVID-19 Spread in Saudi Arabia: Modeling, Simulation and Analysis. Int J Environ Res Public Health. 2020;17(21):7744. Published 2020 Oct 23. doi:10.3390/ijerph17217744

13. Zaplotnik Ž, Gavrić A, Medic L. Simulation of the COVID-19 epidemic on the social network of Slovenia: Estimating the intrinsic forecast uncertainty. PLoS One. 2020;15(8):e0238090. doi:10.1371/journal.pone.0238090

14. Shereen M, Khan S, Kazmi A, Bashir N, Siddique R. COVID-19 infection: Origin, transmission, and characteristics of human coronaviruses. J Adv Res. 2020;24:91-98. doi:10.1016/j.jare.2020.03.005 (4.1)

15. Larsen J, Martin M, Martin J, Kuhn P, Hicks J. Modeling the Onset of Symptoms of COVID-19. Front Public Health. 2020;8. doi:10.3389/fpubh.2020.00473

16. Tan K, Perudin A. The "Geopolitical" Factor in the Syrian Civil War: A Corpus-Based Thematic Analysis. Sage Open. 2019;9(2):215824401985672. doi:10.1177/2158244019856729

17. Abbara A, Blanchet K, Sahloul Z, Fouad F, Coutts A, Maziak W. The Effect of the Conflict on Syria's Health System and Human Resources for Health. World Health Popul. 2015;16(1):87-95. doi:10.12927/whp.2015.24318

18. BKumar KVA, Sahana MN. Exponential Growth Impact of COVID-19 Pandemic- World Scenario, Preventive Measures and Drug Preferences. Health Sci J. 2020; Sp. Iss 1: 006. doi:10.36648/1791809X.S1.006.

19. Health Directorates. DHIS 2. Dhis2.healthdirectorate.com. https://dhis2.healthdirectorate.com:8007/dhis-web-dashboard/\#/.

20. Elferruh Y. Weekly Update of COVID-19 Situation in Northwest Syria. Presentation presented at the: 2020; Turkey - Gaziantep. NWS COVID-19 Taskforce meeting.

21. Early Warning Alert and Response Network EWARN NWS. COVID-19 Surveillance - North West Syria. Situation Report - 173. 15 December 2020. Gaziantep - Turkey: EWARN; 2020.

22. Carcione J, Santos J, Bagaini C, Ba J. A Simulation of a COVID-19 Epidemic Based on a Deterministic SEIR Model. Front Public Health. 2020;8(ISSN=2296-2565). doi:10.3389/fpubh.2020.00230

23. Kolifarhood G, Aghaali M, Mozafar Saadati H, et al. Epidemiological and Clinical Aspects of COVID19; a Narrative Review. Arch Acad Emerg Med. 2020;8(1):e41. Published 2020 Apr 1

24. Gao S, Tu Y, Wang J. Basic reproductive number for a general hybrid epidemic model. Adv Differ Equ. 2018;2018(1). doi:10.1186/s13662-018-1707-7

25. van den Driessche $P$, Watmough J. Further Notes on the Basic Reproduction Number. In: Brauer F., van den Driessche P., Wu J. (eds) Mathematical Epidemiology. Lecture Notes in Mathematics. 2008; vol 1945. ISSN: 978-3-540-78910-9:159-178. doi:10.1007/978-3-540-78911-6_6

26. Nishiura H, Chowell G. The Effective Reproduction Number as a Prelude to Statistical Estimation of Time-Dependent Epidemic Trends. Mathematical and Statistical Estimation Approaches in Epidemiology. 2009;103-121. doi:10.1007/978-90-481-2313-1_5

27. Okabe Y, Shudo A. A Mathematical Model of Epidemics-A Tutorial for Students. Mathematics. 2020;8(7):1174. doi:10.3390/math8071174

28. The Royal Society. Reproduction Number (R) And Growth Rate (R) Of The COVID-19 Epidemic In The UK: Methods Of Estimation, Data Sources, Causes Of Heterogeneity, And Use As A Guide In 
Policy Formulation. Preprint Paper: The Royal Society; 2020:10. https://royalsociety.org//media/policy/projects/set-c/set-covid-19-R-estimates.pdf?la=en-

GB\&hash=FDFFC11968E5D247D8FF641930680BD6. Accessed December 25, 2020.

29. Musa S, Zhao S, Wang M, Habib A, Mustapha U, He D. Estimation of exponential growth rate and basic reproduction number of the coronavirus disease 2019 (COVID-19) in Africa. Infect Dis Poverty. 2020;9(1). doi:10.1186/s40249-020-00718-y

30. Katul G, Mrad A, Bonetti S, Manoli G, Parolari A. Global convergence of COVID-19 basic reproduction number and estimation from early-time SIR dynamics. PLoS One. 2020;15(9):e0239800. doi:10.1371/journal.pone.0239800

31. Rai B, Shukla A, Dwivedi LK. Estimates of serial interval for COVID-19: A systematic review and meta-analysis. Clin Epidemiol Glob Health. 2021;9:157-161. doi:10.1016/j.cegh.2020.08.007

32. Challen R, Brooks-Pollock E, Tsaneva-Atanasova K, Danon L. Meta-analysis of the SARS-CoV-2 serial interval and the impact of parameter uncertainty on the COVID-19 reproduction number. BMJ. 2020; Blueprint. doi:10.1101/2020.11.17.20231548

33. Park M, Cook A, Lim J, Sun Y, Dickens B. A Systematic Review of COVID-19 Epidemiology Based on Current Evidence. J Clin Med. 2020;9(4):967. doi:10.3390/jcm9040967

34. Karia R, Gupta I, Khandait H, Yadav A, Yadav A. COVID-19 and its Modes of Transmission. SN Compr Clin Med. 2020;2(10):1798-1801. doi:10.1007/s42399-020-00498-4

35. Health Cluster for Syria - Turkey hub. COVID-19 Response Tracking Dashboard - Northwest Syria. Power BI Report. App.powerbi.com.

https://app.powerbi.com/view?r=eyJrljoiNTRiMmZiMTAtNWYzZCOOM2RmLWFkOTktZWZIMjQ4 NmFhOWVhliwidCI6ImY2MTBjMGI3LWJkMjQtNGIzOSO4MTBiLTNkYzI4MGFmYjU5MCIsImMiOjh 9\&pageName=ReportSectionb57388c4c756b1036a93. Published 2020. Accessed December 7, 2020.

36. Howard J, Huang A, Li Z et al. Face Masks Against COVID-19: An Evidence Review. Europe PMC. 2020; Preprinted Paper. doi:10.20944/preprints202004.0203.v4

37. Rizki S, Kurniawan A. Efficacy of Cloth Mask in Reducing COVID-19 Transmission: A Literature Review. Kesmas: National Public Health Journal. 2020;15(2). doi:10.21109/kesmas.v15i2.3893

38. Lee B. Minimum Sizes of Respiratory Particles Carrying SARS-CoV-2 and the Possibility of Aerosol Generation. Int J Environ Res Public Health. 2020;17(19):6960. doi:10.3390/ijerph17196960

39. REACH Initiative. COVID-19 Knowledge, Attitudes and Practices (KAP) Survey: Northwest Syria August - September 2020 (Round 4). Gaziantep: REACH Initiative; 2020. https://reliefweb.int/sites/reliefweb.int/files/resources/REACH_SYR_Factsheet_KAP4_Covid_N WS_TK_21.10.20-2.pdf. Accessed December 25, 2020.

40. Williams J. Models for the Study of Infection in Populations. Handbook of Models for Human Aging. 2006;165-182. doi:10.1016/b978-012369391-4/50016-3; ISBN:9780123693914

41. Office for the Coordination of Humanitarian Affairs OCHA. Syrian Arab Republic: COVID-19 Response Update No.12. Situation Overview. OCHA;2020. https://reliefweb.int/sites/reliefweb.int/files/resources/final_covid_response_update_no._12.p df. Accessed December 25, 2020.

42. Rees $E$, Nightingale $E$, Jafari $Y$ et al. COVID-19 length of hospital stay: a systematic review and data synthesis. BMC Med. 2020;18(1). doi:10.1186/s12916-020-01726-3

43. The UN Refugee Agency UNHCR. North-West Syria, Cross-Border Humanitarian Response Sheet, July 2020. UNHCR; 2020. https://reliefweb.int/sites/reliefweb.int

44. Office for the Coordination of Humanitarian Affairs. Syrian Arab Republic: Preparedness and Response To COVID-19. OCHA; 2020. 
https://www.humanitarianresponse.info/sites/www.humanitarianresponse.info/files/document s/files/covid-19 response first monitoring report 14 july 2020.pdf

45. Gillson I, Muramatsu K. Trade and COVID-19 Guidance Note: Health Services Trade And The COVID19 Pandemic. World Bank Group; 2020:1. http://documents1.worldbank.org/curated/en/804331588657997511/pdf/Health-ServicesTrade-and-the-COVID-19-Pandemic.pdf. Accessed December 26, 2020

46. Turan C, Hacımustafaoğlu M. What is The RO Number and Clinical Significance in Infectious Diseases?. Journal of Pediatric Infection. 2020;14(1):47-48. doi:10.5578/ced.202008

47. Spiegel $P$, Musani A, Truelove $S$, Harlass $S$, Van Kerkhove M. Why is COVID-19 NOT Transmitting in Humanitarian Settings as Expected...or is it?. Presentation presented at the: 2020; Baltimore, Maryland

48. Alzoubi Z, lyad K, Othman M, Alnahhas H, Abdulaziz Hallaj O. Reinventing State: Health Governance in Syrian Opposition-Held Areas. Beirut: Friedrich-Ebert-Stiftung; 2019:3

49. Health Cluster for Syria - Turkey hub. Turkey Cross Border. Gaziantep: OCHA; 2020:1. https://www.humanitarianresponse.info/sites/www.humanitarianresponse.info/files/document s/files/turkey_health_cluster_bulletin_march_2020.pdf. Accessed December 26, 2020.

50. Li Q, Guan X, Wu P et al. Early Transmission Dynamics in Wuhan, China, of Novel CoronavirusInfected Pneumonia. New England Journal of Medicine. 2020;382(13):1199-1207. doi:10.1056/nejmoa2001316

51. Zhao S, Musa S, Lin Q et al. Estimating the Unreported Number of Novel Coronavirus (2019-nCoV) Cases in China in the First Half of January 2020: A Data-Driven Modelling Analysis of the Early Outbreak. J Clin Med. 2020;9(2):388. doi:10.3390/jcm9020388

52. Anastassopoulou C, Russo L, Tsakris A, Siettos C. Data-based analysis, modelling and forecasting of the COVID-19 outbreak. PLoS One. 2020;15(3):e0230405. doi:10.1371/journal.pone.0230405

53. Zhao S, Chen H. Modeling the epidemic dynamics and control of COVID-19 outbreak in China. Quantitative Biology. 2020;8(1):11-19. doi:10.1007/s40484-020-0199-0

54. Dur-e-Ahmad M, Imran M. Transmission Dynamics Model of Coronavirus COVID-19 for the Outbreak in Most Affected Countries of the World. International Journal of Interactive Multimedia and Artificial Intelligence. 2020;6(2):4. doi:10.9781/ijimai.2020.04.001

55. Mizumoto K, Kagaya K, Chowell G. Early epidemiological assessment of the transmission potential and virulence of coronavirus disease 2019 (COVID-19) in Wuhan City, China, January-February, 2020. BMC Med. 2020;18(1). doi:10.1186/s12916-020-01691-x

56. Zhu H, Li Y, Jin X et al. Transmission dynamics and control methodology of COVID-19: A modeling study. Appl Math Model. 2020;89:1983-1998. doi:10.1016/j.apm.2020.08.056

57. Sun T, Wang Y. Modeling COVID-19 epidemic in Heilongjiang province, China. Chaos, Solitons \& Fractals. 2020;138:109949. doi:10.1016/j.chaos.2020.109949

58. Davies N, Klepac P, Liu Y, Prem K, Jit M, Eggo R. Age-dependent effects in the transmission and control of COVID-19 epidemics. Nat Med. 2020;26(8):1205-1211. doi:10.1038/s41591-020-09629

59. Wang $\mathrm{L}$, Wang J, Zhao $\mathrm{H}$ et al. Modelling and assessing the effects of medical resources on transmission of novel coronavirus (COVID-19) in Wuhan, China. Mathematical Biosciences and Engineering. 2020;17(4):2936-2949. doi:10.3934/mbe.2020165

60. Aghaali M, Kolifarhood G, Nikbakht R, Saadati H, Hashemi Nazari S. Estimation of the serial interval and basic reproduction number of COVID-19 in Qom, Iran, and three other countries: A datadriven analysis in the early phase of the outbreak. Transbound Emerg Dis. 2020;67(6):2860-2868. doi:10.1111/tbed.13656 
61. Jung S, Akhmetzhanov A, Hayashi K et al. Real-Time Estimation of the Risk of Death from Novel Coronavirus (COVID-19) Infection: Inference Using Exported Cases. J Clin Med. 2020;9(2):523. doi:10.3390/jcm9020523

62. Al-Raeei M. The basic reproduction number of the new coronavirus pandemic with mortality for India, the Syrian Arab Republic, the United States, Yemen, China, France, Nigeria and Russia with different rate of cases. Clin Epidemiol Glob Health. 2020;9:147-149. doi:10.1016/j.cegh.2020.08.005

63. Zhao $S$, Lin $Q$, Ran J et al. Preliminary estimation of the basic reproduction number of novel coronavirus (2019-nCoV) in China, from 2019 to 2020: A data-driven analysis in the early phase of the outbreak. International Journal of Infectious Diseases. 2020;92:214-217. doi:10.1016/j.ijid.2020.01.050

64. Read J, Bridgen J, Cummings D, Ho A, Jewell C. Novel coronavirus 2019-nCoV: early estimation of epidemiological parameters and epidemic predictions. 2020. doi:10.1101/2020.01.23.20018549

65. Wu J, Leung K, Leung G. Nowcasting and forecasting the potential domestic and international spread of the 2019-nCoV outbreak originating in Wuhan, China: a modelling study. The Lancet. 2020;395(10225):689-697. doi:10.1016/s0140-6736(20)30260-9

66. Tian H, Liu Y, Li Y et al. An investigation of transmission control measures during the first 50 days of the COVID-19 epidemic in China. Science (1979). 2020;368(6491):638-642. doi:10.1126/science.abb6105

67. Riou J, Althaus C. Pattern of early human-to-human transmission of Wuhan 2019 novel coronavirus (2019-nCoV), December 2019 to January 2020. Eurosurveillance. 2020;25(4). doi:10.2807/1560-7917.es.2020.25.4.2000058

68. Tian J, Wu J, Bao Y et al. Modeling analysis of COVID-19 based on morbidity data in Anhui, China. Mathematical Biosciences and Engineering. 2020;17(4):2842-2852. doi:10.3934/mbe.2020158

69. Zhuang Z, Zhao S, Lin Q et al. Preliminary estimates of the reproduction number of the coronavirus disease (COVID-19) outbreak in Republic of Korea and Italy by 5 March 2020. International Journal of Infectious Diseases. 2020;95:308-310. doi:10.1016/j.ijid.2020.04.044

70. Xu C, Dong Y, Yu X et al. Estimation of reproduction numbers of COVID-19 in typical countries and epidemic trends under different prevention and control scenarios. Front Med. 2020;14(5):613622. doi:10.1007/s11684-020-0787-4

71. Kuniya T. Prediction of the Epidemic Peak of Coronavirus Disease in Japan, 2020. J Clin Med. 2020;9(3):789. doi:10.3390/jcm9030789

72. Rahman B, Aziz I, Khdhr F, Mahmood D. Preliminary Estimation of the Basic Reproduction Number of SARS-CoV-2 in the Middle East. 2020. doi:10.2471/blt.20.262295

73. Nguemdjo U, Meno F, Dongfack A, Ventelou B. Simulating the progression of the COVID-19 disease in Cameroon using SIR models. PLOS One. 2020;15(8):e0237832. doi:10.1371/journal.pone.0237832

74. Ibrahim M, Al-Najafi A. Modeling, Control, and Prediction of the Spread of COVID-19 Using Compartmental, Logistic, and Gauss Models: A Case Study in Iraq and Egypt. Processes. 2020;8(11):1400. doi:10.3390/pr8111400

75. Sahafizadeh E, Sartoli S. Epidemic curve and reproduction number of COVID-19 in Iran. J Travel Med. 2020;27(5). doi:10.1093/jtm/taaa077

76. Khosravi A, Chaman R, Rohani-Rasaf M, Zare F, Mehravaran S, Emamian M. The basic reproduction number and prediction of the epidemic size of the novel coronavirus (COVID-19) in Shahroud, Iran. Epidemiol Infect. 2020;148. doi:10.1017/s0950268820001247 
77. Giordano G, Blanchini F, Bruno R et al. Modelling the COVID-19 epidemic and implementation of population-wide interventions in Italy. Nat Med. 2020;26(6):855-860. doi:10.1038/s41591-0200883-7

78. Ke R, Romero-Severson E, Sanche S, Hengartner N. Estimating the reproductive number RO of SARS-CoV-2 in the United States and eight European countries and implications for vaccination. 2020. doi:10.1101/2020.07.31.20166298

79. Noreen N, Naveed I, Dil S, Niazi SUK, Saleem S, Mohiuddin N, Khan NU, Noor B, Khan MA \& Khan FK. Trend analysis of exponential increase of COVID-19 cases in Pakistan: An interpretation. Global Biosecurity, 2020; 1(4).

80. Alsayed A, Sadir H, Kamil R, Sari H. Prediction of Epidemic Peak and Infected Cases for COVID-19 Disease in Malaysia, 2020. Int J Environ Res Public Health. 2020;17(11):4076. doi:10.3390/ijerph17114076

81. Crokidakis N. Modeling the early evolution of the COVID-19 in Brazil: Results from a SusceptibleInfectious-Quarantined-Recovered (SIQR) model. International Journal of Modern Physics C. 2020;31(10):2050135. doi:10.1142/s0129183120501351

82. Tuite A, Fisman D, Greer A. Mathematical modelling of COVID-19 transmission and mitigation strategies in the population of Ontario, Canada. Can Med Assoc J. 2020;192(19):E497-E505. doi:10.1503/cmaj.200476

83. Dharmaratne S, Sudaraka S, Abeyagunawardena I, Manchanayake K, Kothalawala M, Gunathunga W. Estimation of the basic reproduction number (RO) for the novel coronavirus disease in Sri Lanka. Virol J. 2020;17(1). doi:10.1186/s12985-020-01411-0 


\section{Declaration}

Manuscript title: Simulation of the Progression of the COVID-19 Disease in Northwest Syria Using Basic and Adjusted SIR Models

Corresponding author: Orwa Al Abdulla.

- Ethics approval and consent to participate: the research does not include human participants directly or human tissue.

- Consent of publication: All the authors irrevocably authorize and grant their full consent to the corresponding author of the manuscript to: (1) enter into an exclusive publishing agreement with Conflict and Health

- Availability of data and materials:

○ The datasets used and/or analysed during the current study are available from the corresponding author on reasonable request.

- The datasets analysed during the current study are available in Northwest Syria DHIS II Platform: https://dhis2.healthdirectorate.com:8007/dhisweb-commons/security/login.action

- Competing interests: The authors declare that they have no competing interests.

- Funding: No fund was obtained or used for this research.

- Authors' Contributions:

O Orwa Al Abdulla: Literature review, methodology, data collection, data analysis, data interpretation, writing original draft, visualization

○ Agneta Kallström: Literature search, writing original draft, review and editing

○ Jussi Kauhanen: validation, review and editing, project administration

○ Camilo Valderrama: review and editing.

- Authors' information:

O Orwa Al Abdulla: (MSc) is a Ph.D. graduate studying at the University of Eastern Finland, Faculty of Health Sciences, Institute of Public Health and Clinical Nutrition. His doctoral dissertation is related to the COVID-19 outbreak in a conflict-affected area, northwest Syria. He has experience in humanitarian coordination and response. 
Currently, he works for the health cluster in Turkey for the humanitarian response in northwest Syria.

- Agneta Kallström (B.A.) is a Ph.D. graduate studying at the University of Eastern Finland, Faculty of Health Sciences, Institute of Public Health and Clinical Nutrition. Her doctoral dissertation is related to violence against health care in Syria.

○ Jussi Kauhanen (MD, MPH, Ph.D.) is a Professor of Public Health, Director Institute of Public Health and Clinical Nutrition, University of Eastern Finland. One of his group's current projects, 'Culture, conflicts, and public health', is concerning with the public health implications for people living in conflict areas or who are affected by humanitarian crises.

o Camilo Valderrama: (MD, MS.c, Ph.D.) is engaged in the humanitarian response in NWS, a current health coordinator, and a former coordinator of the health cluster for northwest Syria humanitarian response. 
Figures

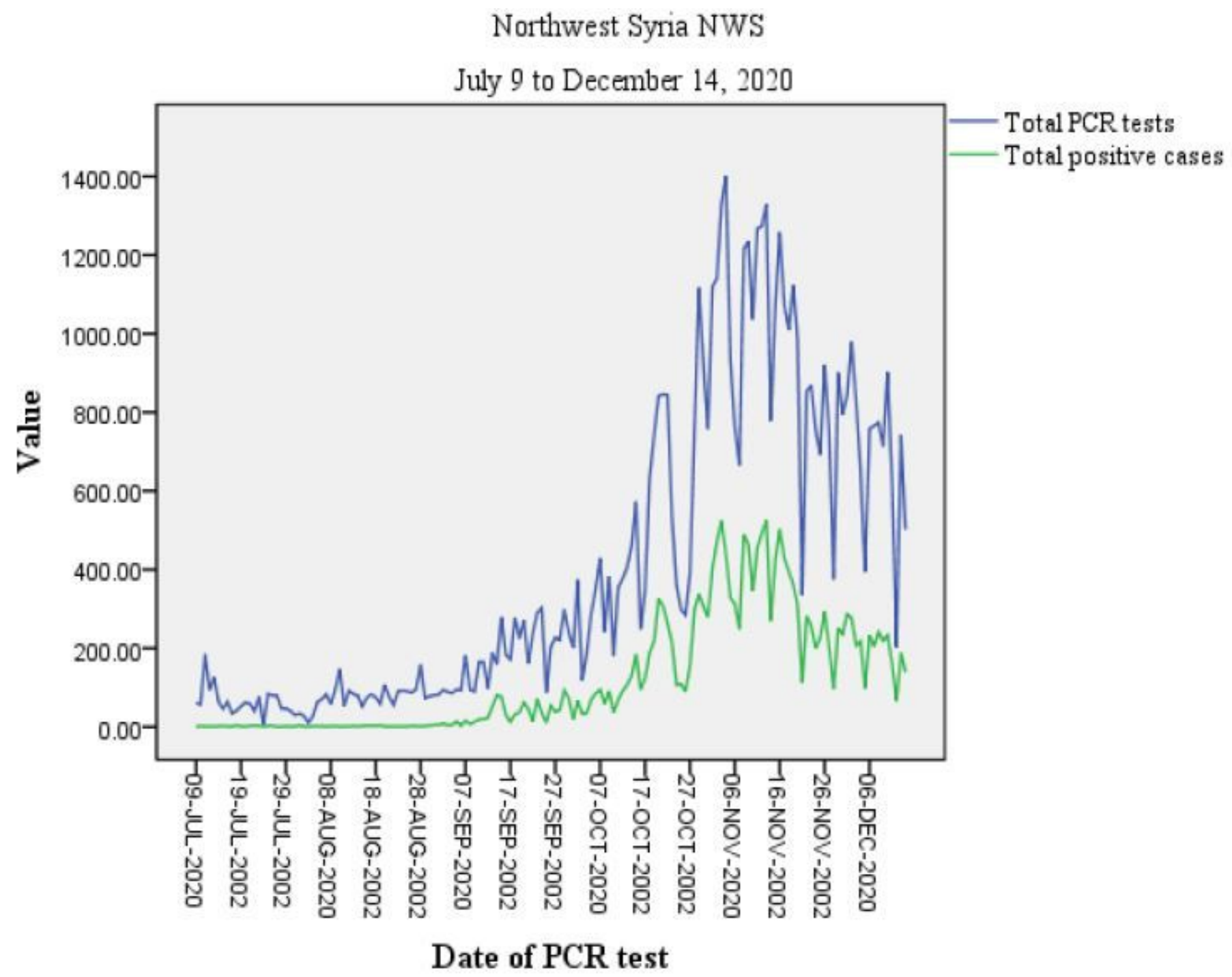

Figure 1

Due to technical limitations, the caption for this figure can be found in the manuscript file. 


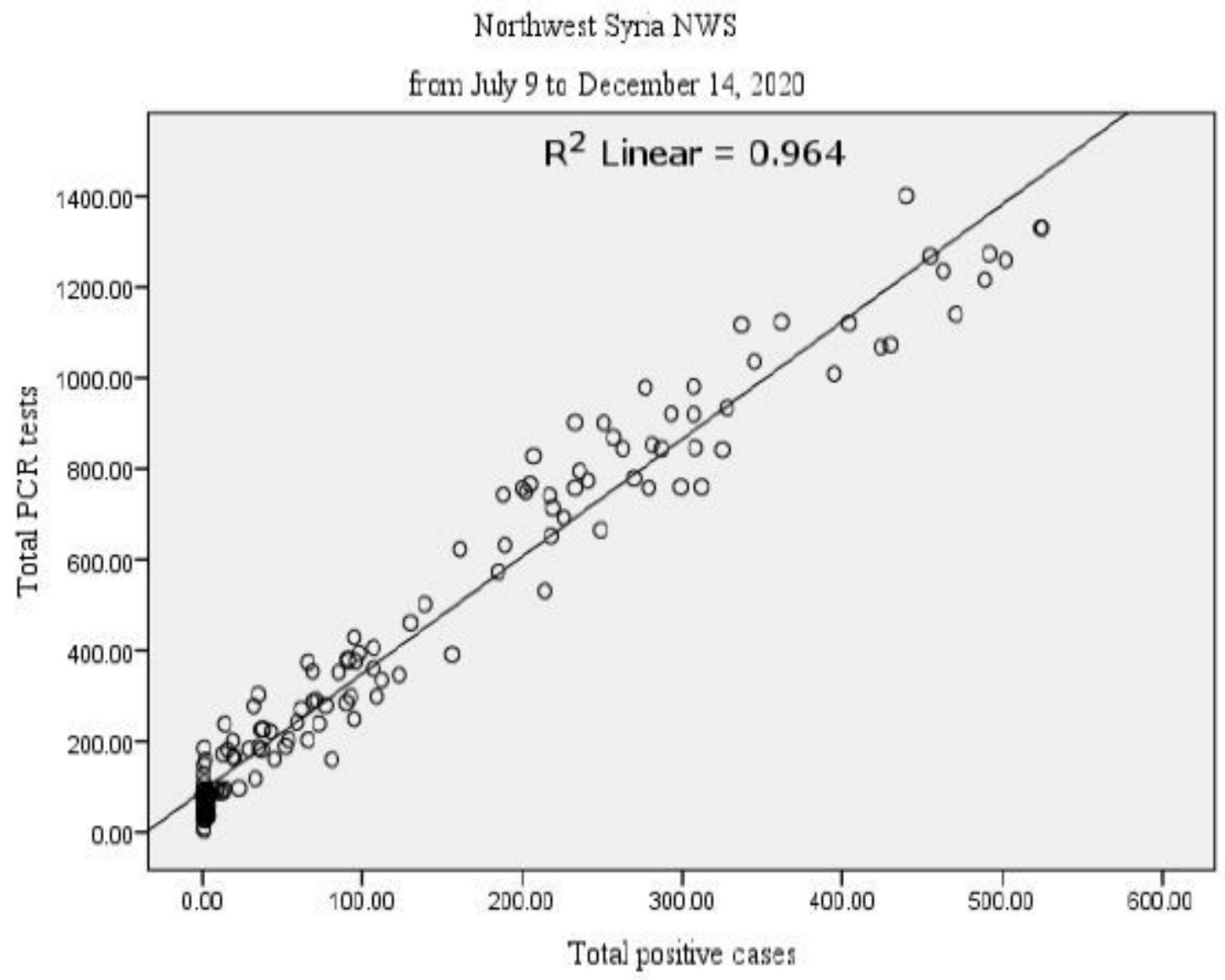

Figure 2

Due to technical limitations, the caption for this figure can be found in the manuscript file. 


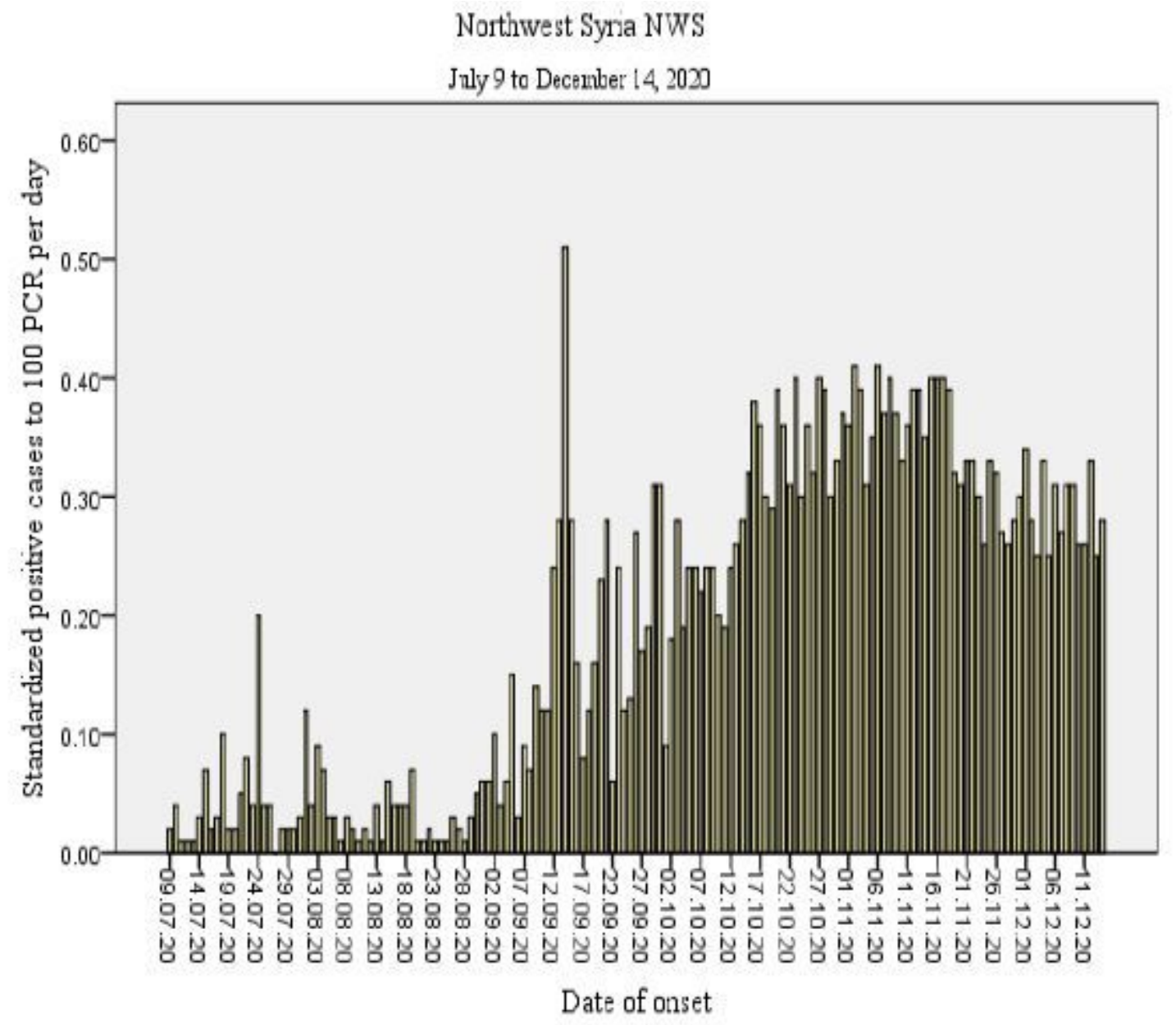

Figure 3

Due to technical limitations, the caption for this figure can be found in the manuscript file. 


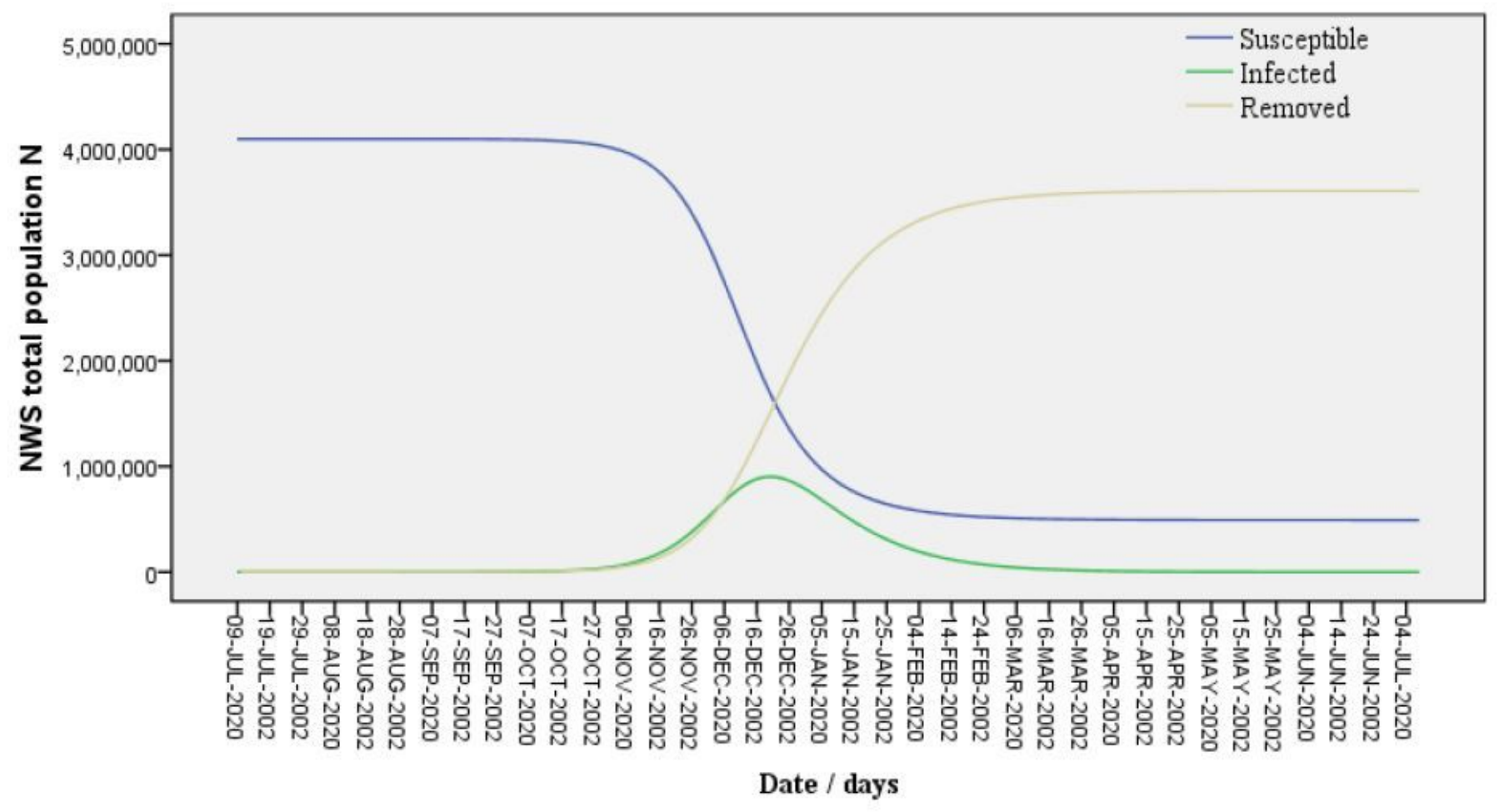

\section{Figure 4}

Due to technical limitations, the caption for this figure can be found in the manuscript file.

Northwest Syria NWS

from July 9,2020 to July 8, 2021

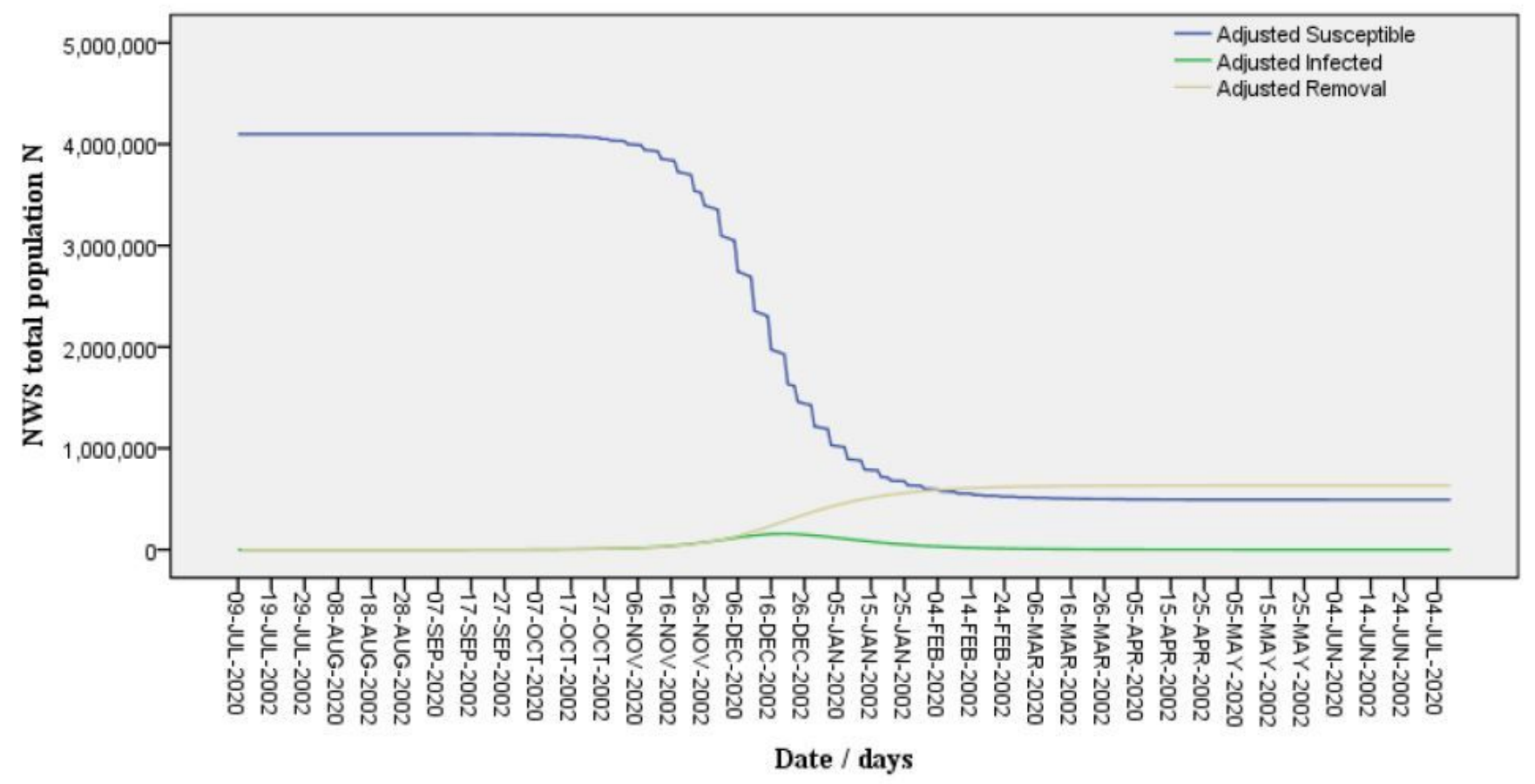

Figure 5

Due to technical limitations, the caption for this figure can be found in the manuscript file. 
Northwest Syria NWS

from July 9, 2020 to July 8, 2021

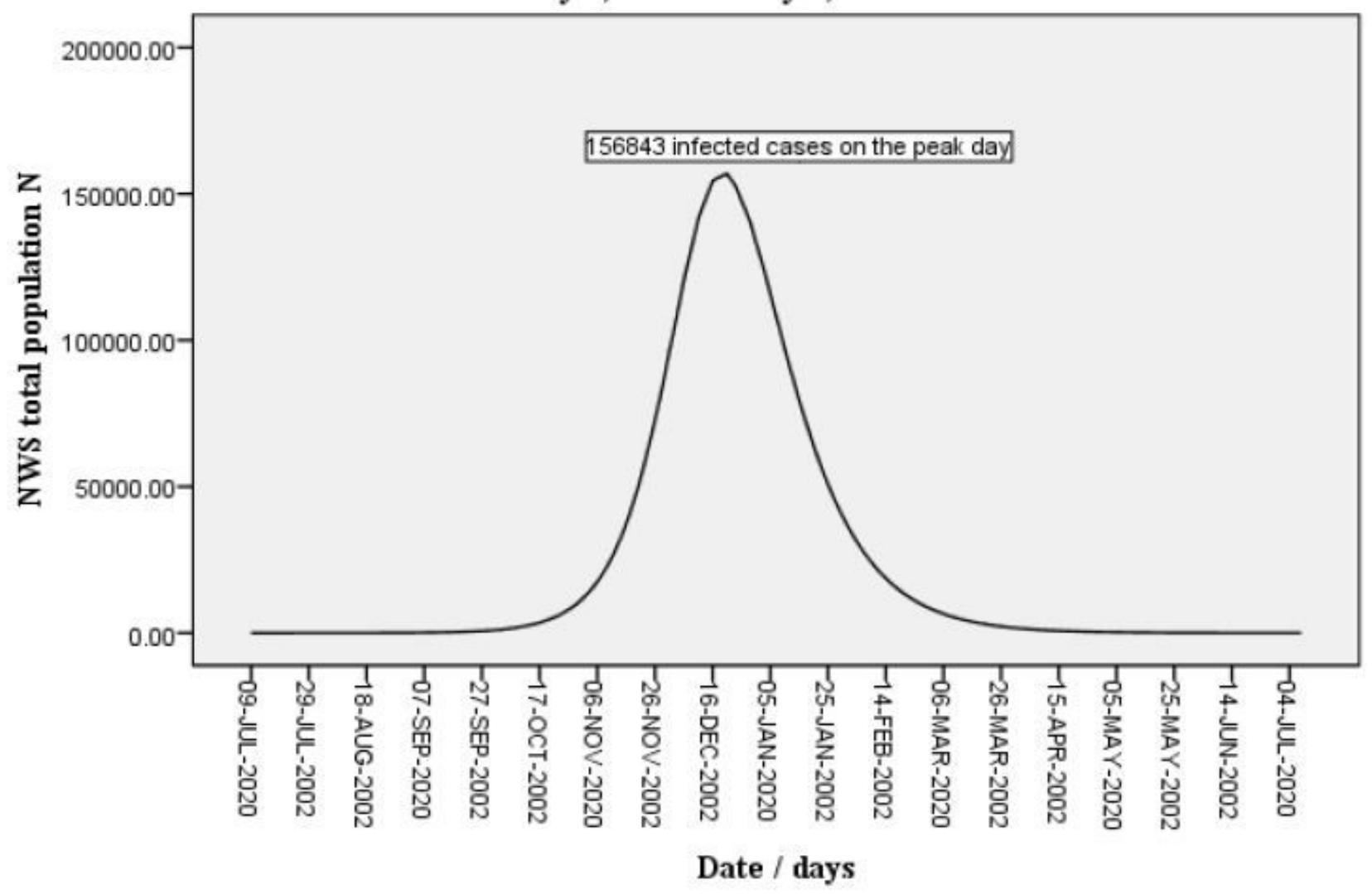

Figure 6

Due to technical limitations, the caption for this figure can be found in the manuscript file. 
Northwest Syria NWS July 9, 2020 until July 8, 2021

July 9, 2020 until July 8, 2021

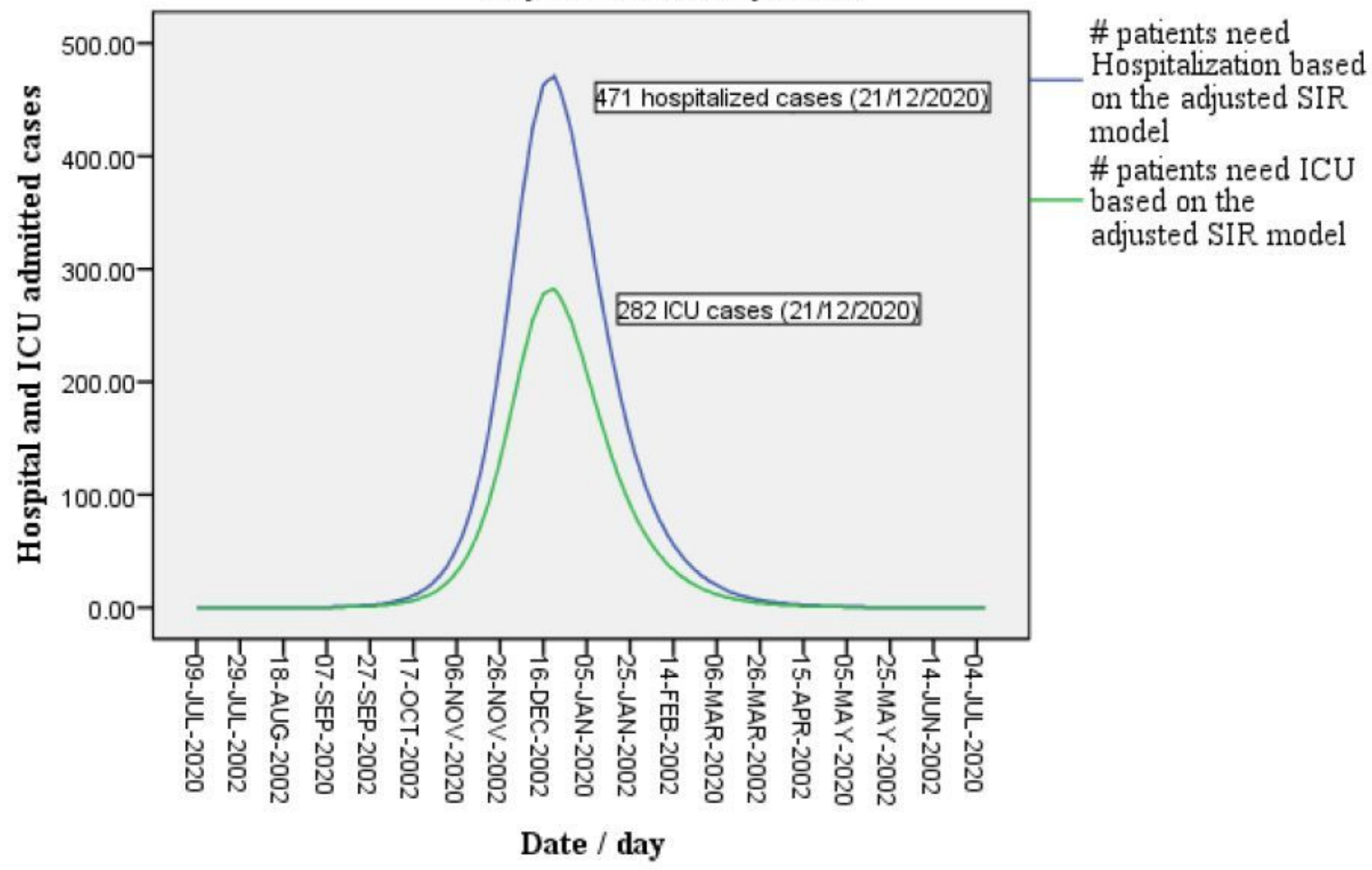

Figure 7

Due to technical limitations, the caption for this figure can be found in the manuscript file. 


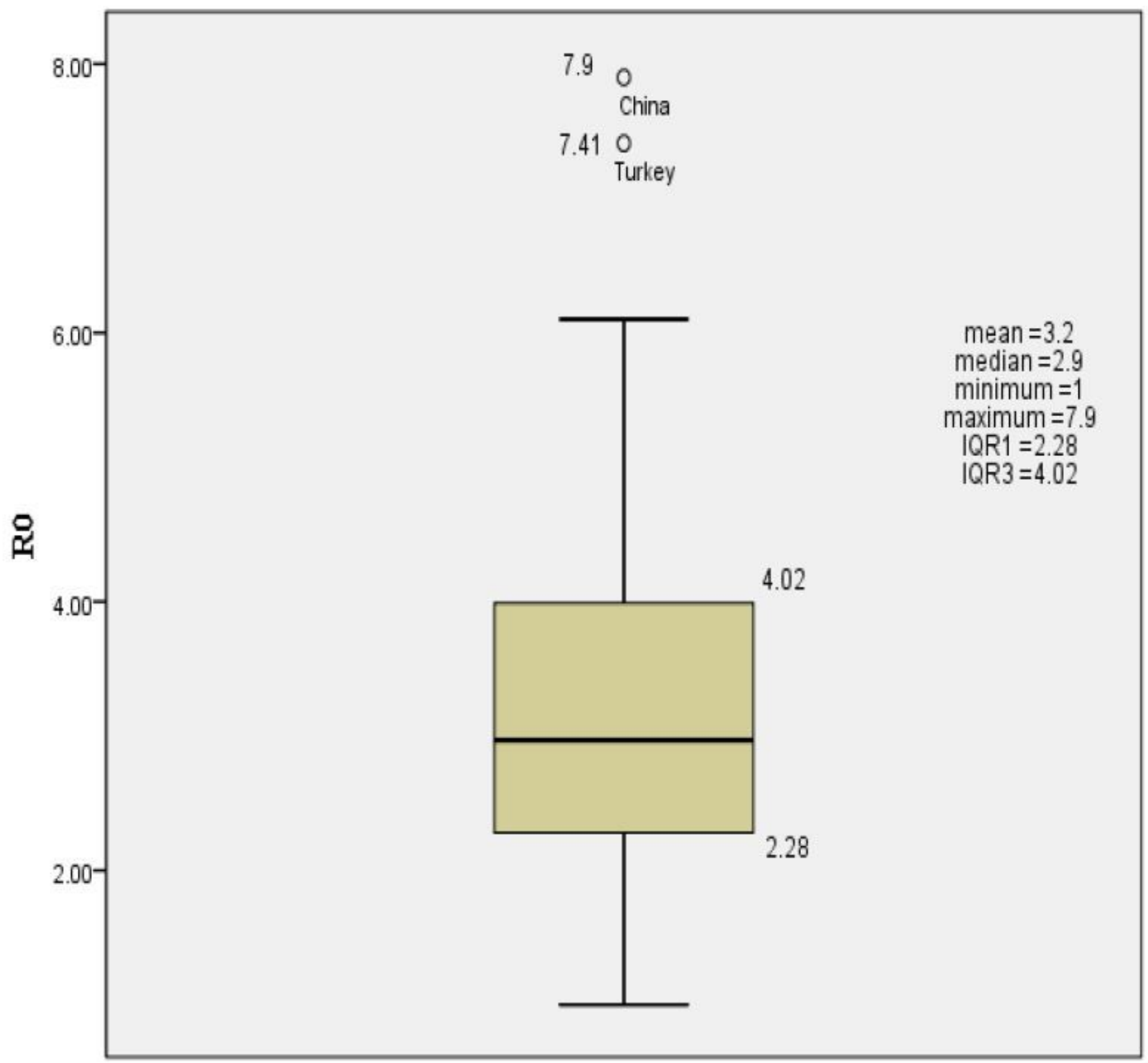

Figure 8

Due to technical limitations, the caption for this figure can be found in the manuscript file. 